Portland State University

PDXScholar

$5-31-1995$

\title{
Functional Uses of Language in the Conversational Discourse of a Person with Alzheimer's Disease
}

Julie Anne Haun

Portland State University

Follow this and additional works at: https://pdxscholar.library.pdx.edu/open_access_etds

Part of the Bilingual, Multilingual, and Multicultural Education Commons Let us know how access to this document benefits you.

Recommended Citation

Haun, Julie Anne, "Functional Uses of Language in the Conversational Discourse of a Person with Alzheimer's Disease" (1995). Dissertations and Theses. Paper 4923.

https://doi.org/10.15760/etd.6799

This Thesis is brought to you for free and open access. It has been accepted for inclusion in Dissertations and Theses by an authorized administrator of PDXScholar. Please contact us if we can make this document more accessible: pdxscholar@pdx.edu. 


\section{THESIS APPROVAL}

The abstract and thesis of Julie Anne Haun for the Master of Arts in TESOL were presented May 31, 1995, and accepted by the thesis committee and department.

COMMITTEE APPROVALS:

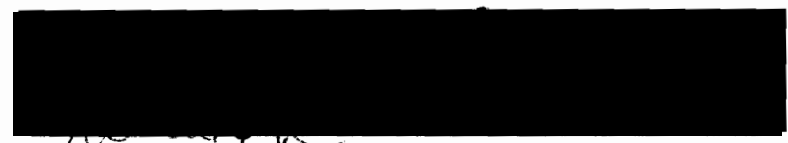

Jęanette DeCarrico, Chair

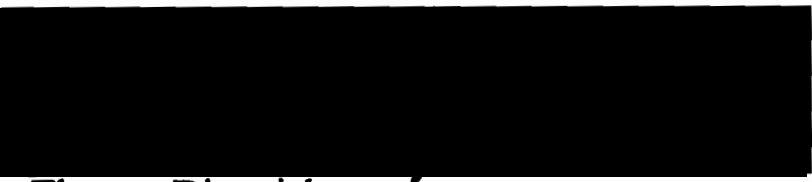

Thomas Dieterich

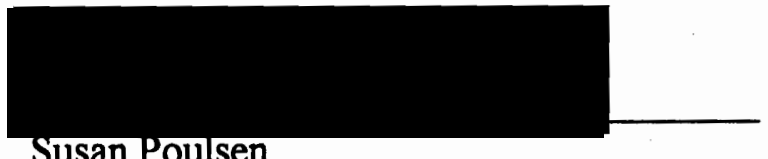

Susan Poulsen

Representative of the Office of Graduate Studies

DEPARTMENT APPROVAL

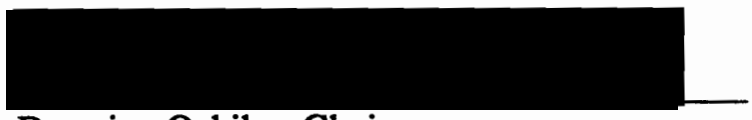

Beatrice Oshika, Chair

Department of Applied Linguistics

ACCEPTED FOR PORTLAND STATE UNIVERSITY BY THE LIBRARY

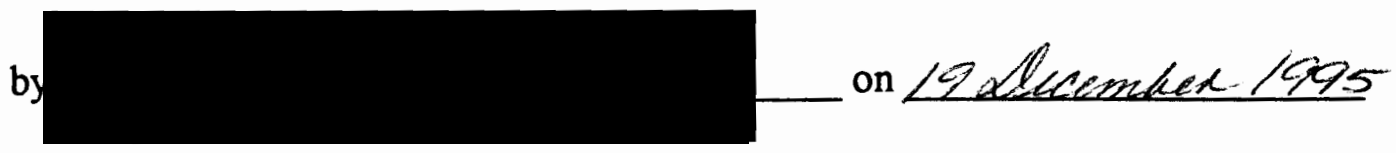




\begin{abstract}
An abstract of the thesis of Julie Anne Haun for the Master of Arts in TESOL presented
\end{abstract} May 31, 1995.

Title: Functional Uses of Language in the Conversational Discourse of a Person with Alzheimer's Disease.

Alzheimer's disease, the most common form of dementia, is estimated to occur in up to sixteen percent of people between the ages of 75 and 84 . Deficits in linguistic skills that effect communication are a hallmark of the disease and have been the primary focus of past Alzheimer's research. Among other deficits, researchers have found that people with Alzheimer's often use indexical expressions without clear referents and convey less information that is relevant to the task they have been asked to perform than healthy subjects. Relatively little research has examined how Alzheimer's subjects use their linguistic knowledge to communicate with others in natural, open-ended interaction. The purpose of the present study was to identify what communication skills remain intact that enable an Alzheimer's subject to maintain conversational fluency despite lexical and pragmatic deficits. The study focused specifically on language skills that play a functional role in facilitating conversation.

The data used in this study consisted of eight naturally occurring conversations between the subject and three interlocutors who had a close relationship with the subject. The interactions were recorded in the Alzheimer's wing of the subject's nursing 
home. The transcribed conversations were analyzed according to three types of functional language drawn from Nattinger and DeCarrico's (1992) work on lexical phrases: (1) conversational maintenance; (2) conversational purpose; and (3) familiar topics. The role played by lexical phrases in facilitating each of these functional categories was also examined.

This study found that the subject had an intact knowledge of functional language skills that allowed her to successfully participate in conversation despite serious language deficits. Within the category of conversational maintenance, the subject retained skills necessary to share control in opening and closing conversations as well as nominating and shifting topics and requesting and offering clarification. In the category of conversational purpose, the subject used functional language to signal utterances intended to convey general politeness, gratitude and compliments as well as informing the interlocutor of her attitude in relation to the content of utterances. The study also found that lexical phrases played a central role in facilitating the subject's use of functional language. 


\title{
FUNCTIONAL USES OF LANGUAGE IN THE CONVERSATIONAL DISCOURSE OF A PERSON WITH ALZHEIMER'S DISEASE
}

by

JULIE ANNE HAUN

A thesis submitted in partial fulfillment of the requirements for the degree of

\author{
MASTER OF ARTS \\ in \\ TESOL
}

Portland State University

1995 


\section{ACKNOWLEDGEMENTS}

I would like to thank my parents, who in their quiet way taught me to persevere and to strive always to do my best. I would also like to thank my advisor, Jan DeCarrico for her untiring enthusiasm, her insight and her willingness to answer all my questions, both large and small. Finally, I would like to thank Tillie and Tim who have taught me the meaning of grace. 


\section{TABLE OF CONTENTS}

PAGE

LIST OF TABLES ................................................................................ vii

CHAPTER

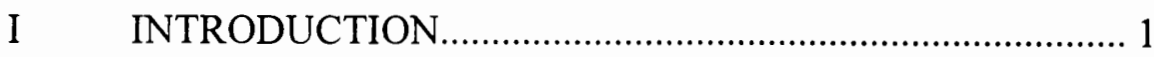

Statement of the Problem.............................................. 1

Statement of Research Questions................................ 10

Research Method.......................................................... 10

Limitations of the Study............................................. 11

II REVIEW OF THE LITERATURE......................................... 15

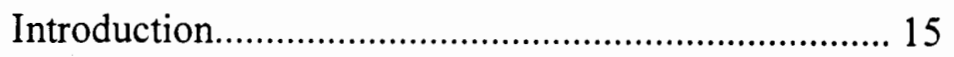

Alzheimer's Disease................................................... 16

Language and Alzheimer's Disease.............................. 20

Lexical Phrases, Functional Language

and Alzheimer's............................................................ 43

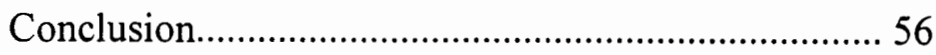

III RESEARCH DESIGN ............................................................ 59

Interaction Analysis.................................................... 59

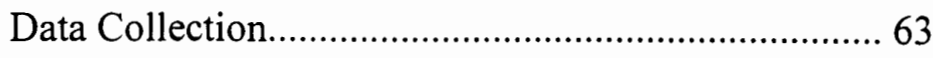

Research Subjects...................................................... 65 
IV RESEARCH FINDINGS.

Introduction. 72

Language Profile. 74

Functional Language................................................ 85

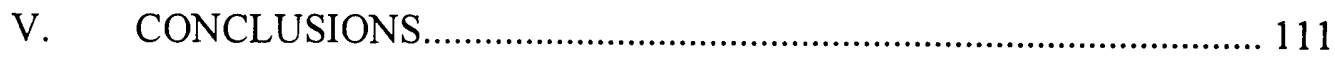

Implications.............................................................. 113

Limitations................................................................ 117

Suggestions for Futher Research..................................... 118

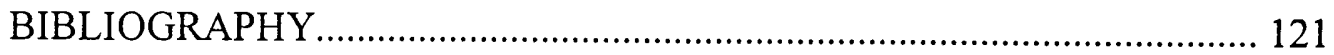

APPENDICES

A. COOKIE THEFT PICTURE........................................... 128

B. TRANSCRIPTION DEVICES ...................................... 129 


\section{LIST OF TABLES}

TABLE

PAGE

1 Examples of Conversational Maintenance Functions with Associated Lexical Phrases.............................................. 52

2 Examples of Conversational Purpose Functions with Associated Lexical Phrases.................................................. 52

3 Necessary Topics and Associated Lexical Phrases................... 53

$4 \quad$ Comparison of Conversational Maintenance and Procedural Tasks..................................................................... 55

5 Comparison of Conversational Purpose Lexical Phrases and Conventional Language Described by Ehernberger Hamilton......................................................................... 56

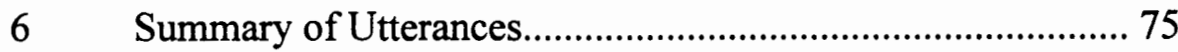

$7 \quad$ Number of Repeated Utterances............................................ 76

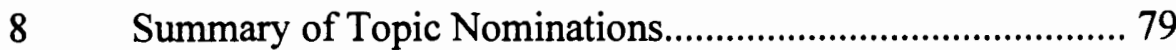

9 Summary of Pronoun Reference.......................................... 81

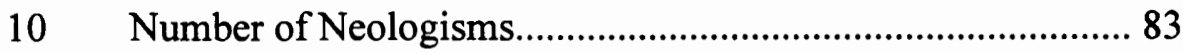




\section{CHAPTER 1}

\section{INTRODUCTION}

Conversing with a person who has Alzheimer's disease presents a unique challenge. Research on people with Alzheimer's has found that their memory is impaired, they have difficulty finding words and their discourse is often unclear. Despite these deficits, people with Alzheimer's maintain an ability to participate in conversation. Alzheimer's research has not been as effective in identifying the intact language skills that facilitate this ability. Information about the kinds of communicative language skills that remain intact could be useful for people who are seeking strategies for communicating more effectively with people who have Alzheimer's disease. The goal of this study is to examine how a person with Alzheimer's disease uses language skills that play a functional role in facilitating conversation. Three categories of functional language drawn from Nattinger and DeCarrico's (1992) work on lexical phrases provide the framework for analysis within the context of natural, open-ended conversation.

For the past three years I have been regularly visiting Tillie, a close friend of my family whom I have known all my life. Tillie lives in a wing of a local nursing home reserved for people who have been diagnosed with some form of dementia. She is 85 
and was diagnosed with Alzheimer's disease in 1988, seven years ago.

The course of Alzheimer's disease varies from person to person, but commonly progresses through roughly three stages (Office of Technology Assessment, 1987; Powell, 1993; Edwards, 1993). In the early stage, the person suffers from mild cognitive decline, begins to lose the ability to remember recent events and is less able to perform complex tasks even though they may be part of a familiar routine (Powell, 1993; Edwards, 1993; Jorm, 1987). In 1987, I stayed with Tillie and her husband in their home for two weeks. Tillie, a woman with enough individual-sized tart pans to serve a dinner party of sixteen and thirteen varieties of pans for molded salad, could manage no more than bologna on slices of bread for dinner. On the two or three days when I told Tillie in the morning that I would not be home for dinner, I returned in the evening to find the oven on with a coffee cup or empty pan inside.

In the intermediate stage, deficits in working memory increase to the point that it interferes with the person's ability to function independently. It was at this stage that Tillie moved out of her house and into a nursing home. She left behind her tart pans, her deluxe Hobart mixer, her toll painting supplies, her sewing machine, her knitting needles. Yet even now, three years later, she never fails to offer me something to eat or to tell me about her latest craft project or church dinner. Even though, of course, she has not had the ability to bake, paint or knit in several years.

In the final stage of Alzheimer's disease, which Tillie has not yet reached, the person loses almost all ability to speak or care for him or herself. Their memory loss is severe and they must rely almost entirely on others to care for them. The overall 
progression of these stages occurs gradually and usually lasts between eight to twelve years. In one study, the life span of individuals from the onset of Alzheimer's symptoms until death ranged from 1.8 to 16 years (Becker and Giacobini, 1990).

The American Geriatrics Society (1991) reports that 15 to 20 percent of us will suffer from some form of dementia once we have reached 85. Dementia is not a disease; rather it is a term which refers to a group of symptoms including, primarily, a progressive deterioration of cognitive abilities. Alzheimer's is only one of several diseases and conditions which cause dementia. Alzheimer's disease as well as Huntington's and Parkinson's diseases are classified as degenerative diseases because they gradually destroy brain tissue. Not all cases of dementia are caused by degenerative diseases, however. Other causes include multi-infarct (repeated minor strokes), certain toxins and some cases of depression (Bayles, 1987; Heston and White, 1991; Mace and Rabins, 1991). At least fifty percent of all cases of dementia are caused by Alzheimer's disease (Thal, 1991; Office of Technology Assessment, 1987).

Tillie has changed in the ways most people do as they age. Her body is shrunken. She is more stooped and shuffles up and down the hallway in large, quilted bedroom slippers. The effect of Alzheimer's physically manifests itself most clearly in her eyes. In a recent photo she is holding her great grandson, her beautiful, heavylidded blue eyes oddly vacant, detached from the rest of her body which is curled around the baby.

In other ways, particularly when we talk, Tillie is the same as I have always known her: her intonation; her laugh; the way she begins her sentences with a long 
"well" followed by a chuckle; the way she crosses her legs and leans toward me when we sit side by side. Her sense of humor remains strong and she can be quite playful. Once, soon after she had moved to the nursing home, we went shopping for baby clothes in a store downtown. Although she asked over and over again whose baby we were shopping for, how old the baby was and whether it was a boy or girl, she seemed quite at home among the racks of sun suits and sleepers. She felt the quality of the cloth and examined the designs with the expertise of someone who has selected clothes for five children and sixteen grandchildren. On the way out of the department store, Tillie paused at a jewelry case which had pearl necklaces on display. "Ooooo," she exclaimed in a stereotyped New York dialect, "look at the poils!" She glanced at me and laughed.

The subjects of our conversations are not always clear. We talk about people I do not know and places I have never been. I am sometimes not even sure what we are talking about, yet somehow the conversations manage to move forward relatively easily. The more I visit the Alzheimer's unit, the more I have begun to feel that at some level Tillie's conversational skills have remained at least partially intact, even though degeneration of language ability is considered a hallmark of Alzheimer's disease (Heston and White, 1991). I have also noted this in the conversation of other people with Alzheimer's disease who live in the unit. It is as though the framework, or scaffolding, which holds conversations together has remained in place even though the content of the conversation has disintegrated.

To learn more about the communication of people with Alzheimer's I turned to the literature on Alzheimer's disease. I began with The 36 Hour Day by Mace and 
Rabins (1991). It is a widely read introduction to taking care of people with Alzheimer's disease and other forms of dementia. I was dismayed by how little had been written on the language of people who have Alzheimer's, and surprised by the frequent characterization of people with Alzheimer's disease as being unable to communicate. Although most of the caretaker literature reported observations similar to my own, noting that the language of people with Alzheimer's appears fluent, the authors quickly added that the language is actually incoherent and empty of meaning (Glickstein, 1988; Heston and White, 1991; Mace and Rabins, 1991; Roberts, 1991). Clem's (1991) description in Caring for the Alzheimer's Patient is typical.

Speech is characterized by an empty, aimless quality. Much of this pointless vocalization is the result of verbal wandering characterized by repetitive speech with little comprehensible meaning. Spoken words are produced correctly and with appropriate fluency but with limited ability to communicate meaningfully (p. 77).

The descriptions of Alzheimer's language in this body of literature are necessarily non technical as they are intended for friends, family members and other caretakers who interact with people who have Alzheimer's. However, I felt their quick dismissal of the patient's ability to "speak with appropriate fluency" might be overlooking more subtle conversational skills which seem to remain in place. Furthermore, specific knowledge of the communicative skills of people with Alzheimer's could be useful for caretakers. In a study conducted by Bayles and Tomoeda (1991) 71 percent of care givers reported that the person they cared for was not able to sustain a conversation or complete sentences. Two factors may have lead to the characterization of people with Alzheimer's as noncommunicative. First, much of 
the discussion on communication in the caretaker literature is based on anecdotal evidence (Fromm and Holland, 1989). As caretakers struggle to describe their communication difficulties when interacting with people who have Alzheimer's, they may misrepresent or overgeneralize the actual linguistic impairment of the person. For example, one caretaker reported that the person with Alzheimer's was not able to pronounce words (Roberts, 1991). However, linguistic research suggests that the phonology system of people with Alzheimer's remains intact (Bayles and Kasniak, 1987).

A second factor which may perpetuate the characterization is the heavy emphasis placed on language impairment in linguistic research. Jane Crisp (1993) remarks that in Alzheimer's research, language is considered primarily in terms of its pathology and its use as a tool for diagnosis. Therefore, the main focus of research has been on documenting the degeneration of language rather than on determining how it is used for communication by people who have the disease. My curiosity and desire to discover why, at least on some level the conversation of people with Alzheimer's appears fluent led me to this research project. What language skills remain intact that enable Tillie's conversations to appear fluent while being at the same time contextually implausible.

Linguistic research in the past fifteen years has attempted to identify which aspects of language are impaired in Alzheimer's. It has focused on the structural form of Alzheimer's language, and research tasks have involved the patient's ability to name objects and to produce well-formed sentences. The research suggests that some 
language skills appear to be well preserved while others degenerate completely. In Communication and Cognition in Normal Aging and Dementia (1987), Bayles and Kasniak review the effect of dementia on the five subsystems of language: phonology, morphology, syntax, semantics and pragmatics. In their review of the literature, they found that while phonology, morphology and syntax remain relatively intact, semantic and pragmatic knowledge degenerates. For example, Kempler, Curtiss and Jackson's (1987) study compared the syntactic and lexical knowledge of healthy elderly and elderly with Alzheimer's and found that the range and frequency of syntactic constructions were similar. However, the lexical range of people with Alzheimer's was lower than that of healthy elderly.

Researchers have found the greatest deficit in semantic and pragmatic knowledge. A number of studies have examined the discourse of people with Alzheimer's disease. The discourse examined is often elicited by asking the subject to describe a common object such as a button or nail. The responses are then examined for qualities such as coherence, phrase length, reference, repetition and vocabulary diversity. For example, Bayles found more frequent use of indefinite reference and reduced phrase length. Heller, Dobbs and Rule (1992) studied the narrative discourse of people with Alzheimer's and found they produced fewer clauses in their descriptions and failed to describe as many main ideas from a story as control subjects. Bayles found that people with Alzheimer's were unable to identify speech acts (e.g. promising, denying and greeting) which occurred within a conversation.

The majority of discussion on the narrative discourse of people with Alzheimer's 
in the linguistics literature, while more analytic, mirrors the descriptions given in the caretaker literature. A statement by Appell, Kertesz and Fisman (1982) sums up the general conclusion drawn by many Alzheimer's researchers about the speech of people with Alzheimer's, "there are many verbal substitutions and the discourse becomes jargon when it loses its communicative purpose, even though small talk or strings of automatically used words remain" (p. 83).

While it is certain that people with Alzheimer's suffer many types of language impairment, the contrived nature of the discourse that has been analyzed for pragmatic competence may have underestimated their actual pragmatic ability. Recently a few Alzheimer's researchers have analyzed the spontaneous, natural conversation of people with Alzheimer's to determine which communicative elements of language remain intact or are impaired. For example, Ripich, Vertes, Whitehouse, Fulton and Ekelman (1991) found that when discourse occurred in a natural conversation, people with Alzheimer's applied speech acts appropriately as well as conforming to turn taking conventions.

One communicative aspect of Alzheimer's language that has not been fully researched is the use of language for functional purposes within conversations. Nattinger and DeCarrico (1992) write that during conversation, participants manipulate not only topics, but the conversational flow as well. In Lexical Phrases and Language Teaching, Nattinger and DeCarrico outline three categories of functional language that operate within social conversation. These include language that is used to maintain conversations (e.g. opening and closing conversations), language that signals the specific purpose of an utterance (e.g. signaling disagreement), and language that marks 
specific topics that commonly arise in casual conversation (e.g. likes and dislikes).

Functional uses of language are often associated with specific conventionalized forms. Nattinger and DeCarrico use the term lexical phrase to describe these conventionalized chunks of language that have a functional role in conversation. For example, the phrase "It's been nice talking to you" conventionally signals the speaker's wish to close the conversation.

In her case study of a person with Alzheimer's disease, Ehernberger Hamilton (1994) found that the subject used a great deal of conventionalized language. She describes this type of speech as prefabricated pieces of language which are derived from culturally shared formulas and from the subject's professional life. Ehernberger Hamilton describes several functions of this conventionalized language and remarks that it is the subject's ability to use this language that allows her to continue to interact socially with others. Although Ehernberger Hamilton does not refer to lexical phrases in her discussion of the conventionalized language used by her subject, it may not be unreasonable to draw a connection between the two. Nattinger and DeCarrico note that "it is our ability to use lexical phrases ... that helps us to speak with fluency" (p. 32). An intact ability to appropriately use functional language to maintain conversations and signal the purpose of utterances might contribute to the perception of conversational fluency that is frequently mentioned in Alzheimer literature. 


\section{STATEMENT OF RESEARCH QUESTIONS}

The potential link between the application of functional language and the perception of conversational fluency forms the core of this thesis. The central question that guides the research is in what ways does a person with Alzheimer's disease use and respond to functional language as a means of negotiating her way through a conversation? The analysis focuses on four sub-questions:

1. Does the subject use or respond to functional language that guides or maintains the flow of conversation?

2. Does the subject use or respond to functional language that provides clues to the speaker's intended purpose of a particular utterance?

3. Does the subject use functional language to discuss familiar topics?

4. What role do lexical phrases play in facilitating the subject's use of functional language?

\section{RESEARCH METHOD}

Research for this thesis is conducted through a case study of a person with Alzheimer's disease. The subject for this study is Tillie, who was described in the introduction of this chapter. The primary focus of the case study is an analysis of the interaction between the subject and her interlocutors during naturally occurring conversations. Eight conversations were recorded in the Alzheimer's unit where Tillie lives and then transcribed. Four of the conversations involve Tillie and myself. Two 
involve Tillie and her primary care giver in the Alzheimer's unit and two include Tillie and her daughter. Each transcript is analyzed to determine the participants' use of functional language based on the three categories outlined by Nattinger and DeCarrico in Lexical Phrases and Language Teaching (1992).

\section{LIMITATIONS OF THE STUDY}

Three issues of concern must be acknowledged regarding the content and research methods used in this study. First, Alzheimer's disease cannot be definitively diagnosed until an autopsy of the brain is performed after death. Becker and Giacobini (1990) write that studies of agreement between clinical diagnosis of the disease and post-mortem diagnosis show between 80 and 100 percent accuracy. However, a study conducted by the National Institute of Neurological and Communicative Disorders and Stroke (NINCDS) (1985) reported only a 68 percent agreement between the two diagnoses. Two potential areas of concern to the current study arise from the issue of the potential for misdiagnosis in Alzheimer's disease. First, is the question of the subject, Tillie's, own diagnosis of Alzheimer's disease. It is possible that Tillie falls within this margin of error and suffers from a dementia other than Alzheimer's. Second, as with all research, the current study relies on information drawn from past studies, in this case studies of people with Alzheimer's disease. It is also possible that subjects involved in these studies, while suffering from some form of dementia, were misdiagnosed as having Alzheimer's disease. However, rather than wait until a time 
when definitive clinical diagnoses can be made, researchers in the field pursue their research with as much accuracy as possible given the limitations in diagnosis.

Alzheimer's researchers often uses terms such as Dementia of the Alzheimer's type (DAT) or suspected Alzheimer's in recognition of this limitation. This research uses the term Alzheimer's yet recognizes that it refers to suspected rather than confirmed cases of Alzheimer's disease.

A second issue of concern involves the use of conversational analysis (CA) as a means of examining the interaction process. The production of conversation requires speakers to apply several systems of language simultaneously. The layering of these systems of language is complex and the current understanding of their orchestration is not complete (Dorval, 1990; Wardhaugh, 1985). Conversational Analysis is a specific tool used by researchers to further their understanding of the process of interaction. At the heart of $\mathrm{CA}$ is the assumption that conversation is composed of patterns which are rule-governed or regular (Schegloff, 1968). Guided by this assumption, researchers examine the transcripts of talk in order to identify and account for these regularities.

Taylor and Cameron (1987) in their critique of Conversational Analysis point out the problem of segmenting spoken utterances into written transcripts. Conversation as it naturally occurs is messy. Speakers begin utterances without finishing them, they stutter, they interrupt one another, they speak simultaneously and sometimes pause for several seconds before speaking. This poses a problem for researchers who must somehow transcribe this unwieldy set of spoken data onto a two dimensional space. The process of transcription requires that the researcher segment utterances into 
decipherable chunks which then imposes an orderliness onto the conversation that does not exist in real life. The conversations for this study were transcribed using conventions recommended by Evelyn Hatch (1992). Please see (appendix B) for an outline of the transcription conventions used.

Directly related to this problem is the difficulty of capturing speaker intonation and non-verbal communication in transcriptions of conversation. In conversation, these two factors play a subtle yet important role in the evolution of meaning within the conversation. While it is possible to incorporate a set of symbols onto the transcript which represent the intonation of each utterance, this research does not do so. Intonation and non-verbal communication, such as pointing gestures, are included in the transcripts only when they are necessary for comprehension of the conversation.

The third issue which must be addressed is the use of a single case study as the primary research method. The debate over qualitative verses quantitative research methods is a familiar one and criticism of case studies as a qualitative research method centers on two points. First, can the findings of a particular case study be generalized to a larger population? While this concern is a valid one, the intent of this research is to explore and describe an area that has not yet been fully examined in Alzheimer's language research in an effort to add another dimension to the growing information on language use in the natural conversations of people with Alzheimer's disease.. The intent is not to make a general statement about the ability of all people with Alzheimer's disease to use and respond to lexical phrases and cohesive devices.

The second point of criticism concerns the reliability of case studies. Would 
several researchers analyzing the same data come to the same conclusions? The nature of qualitative study is that it is subjective, naturalistic and less controlled than quantitative study (Long and Larsen-Freeman, 1991). While these characteristics undoubtedly make replication of a study more difficult, for this research project, the natural and uncontrolled character of the conversations being analyzed are vital to the central point of the thesis. Nunan (1992), in his discussion of case study research methods, outlines five steps the researcher can take to increase the level of reliability in a case study. First, the social position of the researcher in relation to the informant must be carefully described. Second, the choice of the informant must be explained. Third, the social situation and context in which the research was conducted must be explicitly described. Fourth, the framework for analysis must be detailed, including clear definitions of any units of measure which are used. Finally, the methods for collecting data must be explicit. To increase reliability of this case study each of these five points.

\section{$\underline{\text { Summary }}$}

The goal of this research project is to explore what functional language skills remain intact and which seem to be lost in the natural conversation of a person with Alzheimer's disease. The research is conducted through an analysis of eight naturally occurring conversations between an elderly woman who has had Alzheimer's disease for seven years and three adults who do not have the disease. The primary focus of the analysis is the participant's use of functional language within conversations. 


\section{CHAPTER II}

\section{REVIEW OF THE LITERATURE}

Tillie: I don't know if I'm going to go nutty doing things.

Debi: Why do you say that Tillie?

Tillie: Well, I have things all centered and in (unintelligible) and everything, and looks all right=

Debi: $=\mathrm{Mmhmm}=$

Tillie: =and then low and behold it gets all mixed up.

\section{INTRODUCTION}

The impact of Alzheimer's disease on memory and language is central to the confusion experienced by people with Alzheimer's disease in their daily life. This chapter considers the relationships among Alzheimer's disease, language and lexical phrases and their combined effect on people's ability to communicate. The first section provides an overview of Alzheimer's disease, its symptoms and its influence on the operation of memory. The second reviews previous research on linguistic knowledge and language use in people with Alzheimer's disease. The third section describes lexical phrases, their functional role in communication and how findings from Alzheimer's research correspond to the characteristics of lexical phrases. 


\section{ALZHEIMER'S DISEASE}

In 1907 Alois Alzheimer, a German neurologist, wrote an article on dementia. He described the symptoms of a 51 year-old woman in his care which included a progressive loss of memory, confusing speech and an inability to perform simple daily activities. When he performed an autopsy after the woman's death, Alzheimer found two abnormalities in her brain which eventually became known as the distinguishing characteristics of Alzheimer's disease (Henig, 1981; Jorm, 1987).

Alzheimer described the disease as a presenile dementia and for many years it was considered a rare disease that only occurred in people under 65 . In the 1960 's and 1970 's, autopsy studies on the brains of people with senile dementia revealed that the degeneration of brain tissue in senile dementia and presenile dementia was identical. Two abnormal structures appear in the brain of a person with Alzheimer's disease. First, neurofibrillary tangles are present inside brain cells. These tangles are composed of two strands of normally occurring fibers which, in Alzheimer's disease, become wrapped around one another forming a spiral. Second, clusters called neuritic plaques form in the synapses, or gaps, between nerve fibers. At the center of each plaque is a concentration of protein called amyloid which normally does not appear in the brain (Beck, 1991). Neurofibrillary tangles and neuritic plaques are present in the brains of most people over 80. It is the concentration and location of these tangles and plaques within the brain that distinguishes Alzheimer's disease from normal aging (Henig, 
1981).

Today, the medical community no longer makes age-based distinctions, referring to all cases with these symptoms simply as Alzheimer's disease. Alzheimer's disease is also now recognized as the most common cause of dementia in people over 65. Jackson, Katzman and Lessin (1991) state that Alzheimer's disease accounts for 50 percent of all cases of dementia. Estimates on the number of people who suffer from Alzheimer's disease vary. Powell (1993) reports that one percent suffer from Alzheimer's disease between the ages of 65 and 74. Four percent develop Alzheimer's between 75 and 84 and ten and a half percent suffer from the disease after the age of 85 . Jackson et al. report only that thirty-three percent of the population develops Alzheimer's disease by the time they reach 90. The highest figures for Alzheimer's disease come from a study conducted in 1990 which estimates incidence of nearly four percent in people between 65 and 74, sixteen percent in people between 75 and 84, up to forty-five percent in those 85 years and older (Evans et al., 1990). Gathering statistics on the prevalence of Alzheimer's disease is complicated by the fact that it is not always easy to distinguish Alzheimer's disease from other forms of dementia. For example, repeated minor strokes (multi-infarct), depression and exposure to certain heavy metals can all cause symptoms of dementia which are similar to Alzheimer's (Beck, 1991).

Because biopsies of the brain are dangerous and thus rarely performed, Alzheimer's disease is diagnosed through a process of elimination. The National Institute of Neurological and Communicative Disorders and Strokes and the 
Alzheimer's Disease and Related Disorders Association have developed a set of criteria which is widely used for diagnosing the disease. Among the criteria for probable Alzheimer's are:

A. Deficits in two or more areas of cognition;

B. Progressive worsening of memory and other cognitive functions;

C. No disturbance of consciousness;

D. Onset between ages 40 and 90 , most often after age 65 ;

E. Absence of systemic disorders or other brain diseases that of themselves could account for the progressive deficits.

Kawas (1991) lists eight cognitive processes that are typically impaired in Alzheimer's disease. These processes include orientation to time and place, memory, language skills, praxis, attention span, visual perception, problem solving skills and social functions and activities in daily living.

Among these eight processes, memory and language problems are often the first symptoms of Alzheimer's disease (Bayles and Tomoeda, 1991; Jorm, 1987 and Mitchell, 1991). The pattern of neurofibrillary tangles in the brain provides an interesting clue to why memory and language problems are so prevalent in Alzheimer's. The tangles are abnormally concentrated in the hippocampus, which has been linked to memory, and in the left temporal lobe, which has been associated with some aspects of language ability (Morris and Kopelman, 1986; Powell, 1993; Sloan, 1990). Several researchers (Fromm and Holland, 1989; Nicholas, Obler, Albert and Helm-Estabrook, 1985) have compared the effects of Alzheimer's disease and Wernicke's aphasia. 
Wernicke's aphasia results from damage to Wernicke's area, which is located within the left temporal lobe. In both disorders, affected people produce sentences which are grammatical, yet semantically anomalous.

Research on memory loss in Alzheimer's disease has uncovered two findings of interest to the present study. First, several researchers have suggested that long term memory is less affected by Alzheimer's disease than working memory. (Jorm, 1987; Mitchell, 1991). In their review of research on long term memory loss, Morris and Kopelman (1986) suggest that the "age" of a memory is less a factor in its retention than the degree to which it has been used over the years. They found that people with Alzheimer's (until its late stages) are able to draw on salient information that has been established by repetition over a long period of time and has, in their words, become "overlearned" (p. 591).

Second, Alzheimer's disease impairs the Central Executive System (CES) (Morris, 1994). This system coordinates mental processes and operates the immediate storage of information. Its capacity for processing information is limited, therefore when two or more complex tasks are performed simultaneously, the processing demand can exceed its capacity. The deterioration of the CES that is caused by Alzheimer's disease seriously reduces the system's capacity to coordinate mental activities. Consequently, the CES reaches its processing limit even more quickly than occurs in healthy people. As a result, people with Alzheimer's are less able to process complex tasks that place a high demand on the CES (Morris, 1994). These two findings suggest that people with Alzheimer's are more likely to retain and produce chunks of 
information that are well established in long term memory and can be processed with minimal demands on the Central Executive System.

\section{LANGUAGE AND ALZHEIMER'S DISEASE}

The language of people who have Alzheimer's disease has been studied for over twenty years. The first efforts to define the language difficulties of people with Alzheimer's were quantitative studies of lexical knowledge which focused on the manipulation of words in isolation. This focus grew to include research on the language deficits in discourse produced by people with Alzheimer's. Recently, the research focus has expanded once again to include the communicative abilities of people with Alzheimer's within the context of natural interaction.

Each expansion of linguistic research in Alzheimer's disease has provided new insight into the nature and degree of language impairment, and in some cases has challenged the findings of earlier, more narrowly focused research. Discussion of Alzheimer's language in the following three sections corresponds to the three waves of linguistic research. The first section briefly outlines the research on lexical difficulty. The second section discusses research on subject focused discourse analysis and the final section considers research based on interaction analysis.

Research on Lexical Difficulty

Researchers' initial interest in the language of people with Alzheimer's was its use as a tool for diagnosing the disease. Lexical difficulty is a prevalent symptom of 
Alzheimer's and occurs early in the course of the disease (Appell, Kertesz and Fisman, 1982; Nicholas, Obler, Albert and Helm-Estabrooks, 1985; Sanderson, Obler and Albert, 1987). Therefore, it was a natural choice for the attention of researchers. Difficulty in thinking of the names of objects and difficulty in finding the word he or she wants to say are two common forms of lexical difficulty experienced by people with Alzheimer's. Evidence for these difficulties comes from confrontation naming tests and word generation tests which are often subtests of larger diagnostic tests, such as the Boston Diagnostic Aphasia Examination (developed by Goodglass and Kaplan in 1972). Confrontation naming tests require the subject to provide the name for an object or action that is usually represented by a picture. Word generation tests require the subject to list orally as many words as they can which fit into a specified category such as animals or sports. In the early stages of the disease, Alzheimer's subjects usually perform at or near the level of control subjects on confrontation naming tests (Bayles and Kasniak, 1987; Blanken, Dittman, Haas and Wallesch, 1987). On the other hand, their performance on word generation tests (also referred to as word fluency) is consistently lower than control subjects. For example, in a word generation test conducted by Bayles and Kasniak (1987) controls produced an average of 21 words while subjects with mild Alzheimer's produced an average of only 9 words. Therefore, performance on word generation tests is often cited as a better early measure for Alzheimer's disease (Murdoch, Chenery, Wilks and Boyles, 1987; Sanderson, Obler and Albert, 1987).

In addition to providing useful information for diagnosis, lexical difficulty in 
those with Alzheimer's offers researchers the opportunity to gain broader insights into memory and language processing. One example of this is the discussion of why people with Alzheimer's have more difficulty producing words in some situations than in others. Theories of information processing distinguish between automatic and controlled information processing. Stillings (1989) writes that people have only a limited capacity to perform several independent tasks simultaneously, via controlled processing. When forced to consciously attend to a task, a person's processing capacity is more quickly taxed.

Ehernberger Hamilton (1994) refers to this limited capacity when she suggests that the amount of conscious effort required to process a task influences the Alzheimer's subject's performance on lexical tests. Confrontation naming tests place less demand on cognitive processing (Central Executive System) than word generation tests, in which the subject must generate an entire list of semantically related words (Bayles and Kasniak, 1987).

Differences in the processing demand placed on the Central Executive System might also account for the superior lexical performance of Alzheimer's subjects in spontaneous speech when compared with performance in test situations (Blanken, Dittman, Haas and Wallesch, 1987; Ehernberger Hamilton, 1994). Nebes, Martin and Horn (1984) point out that testing situations demand effortful attention of Alzheimer's subjects which diverts their attention away from lexical processing. This is supported by Langer (1978) who writes that people in general are more self-conscious in test situations and as a result, more of their attention is focused on processing incoming 
information. Research on the lexical difficulty experienced by people with Alzheimer's continues to be a primary focus of the literature on language and Alzheimer's disease.

\section{Research on Subject Focused Discourse}

Motivated by their effort to document the type and progression of language degeneration experienced by people with Alzheimer's, researchers have expanded the scope of their research to include not only word level production, but discourse production as well. Subject-focused discourse analysis is based on discourse elicited either through an object or picture description task such as the Cookie Theft Picture, from the Boston Aphasia Diagnostic Examination (see Appendix A), or through short interviews guided by the researcher. The consensus of this body of research is that the discourse of people with Alzheimer's is fluent but pragmatically impaired. (Appell, Kertesz and Fisman, 1982; Hier, Hagenlocker and Shindler, 1985; Nicholas, Obler, Albert and Helms-Estabrooks, 1985; Bayles and Kasniak, 1987; Murdoch, Chenery, Wilks and Boyles, 1987; Sanderson, Obler and Albert, 1987; Fromm and Holland, 1989; Smith, Chenery and Murdoch, 1989; Heller, Dobbs and Rule, 1992). These researchers have identified several features of Alzheimer's discourse which account for its fluency. They have also begun to identify which aspects of pragmatic knowledge are impaired, and to a lesser extent, which aspects remain intact.

Fluency in Alzheimer's Discourse. The clearest contributor to the fluency of discourse among people who have Alzheimer's disease is the long survival of their syntactic system. Researchers who have examined syntax agree that it remains 
undisturbed until late in the course of the disease (Appell, Kertesz and Fisman, 1982; Bayles and Kasniak, 1987; Blanken, Dittman, Haas and Wallesch, 1987; Hier, Hagenlacker and Shindler, 1985; Kempler, Curtiss and Jackson, 1987; Sanderson, Obler and Albert, 1987). In their review of research on syntax, Sanderson et al (1987) report that syntactic ability seems to be maintained independently of semantic and cognitive ability. In a study by Whitaker (1976), a subject in an advanced stage of Alzheimer's was able to do little more than echo comments made by the examiner. When the examiner uttered sentences with grammatical errors, the subject spontaneously echoed the correct response. For example, when the examiner said "there are two chair in this room," the Alzheimer's subject echoed, "there are two chairs in this room." Sentences that contained semantic anomalies such as "the apple was eaten by a stone" were also echoed but without correction.

Researchers disagree over the degree of syntactic complexity subjects with Alzheimer's disease are able to produce when forming sentences. Hier, Hagenlocker and Shindler (1985) report that Alzheimer's subjects produced syntactically simple sentences when compared with control subjects. Blanken, Dittman, Haas and Wallesch (1987) also found that Alzheimer's subjects tended to produce sentences with fewer complex clause structures. However, they point out that their subjects did produce some longer, complex sentences, demonstrating that their knowledge of the syntactic skills associated with these forms were still intact. Other researchers have found that the syntactic structures produced by Alzheimer's subjects are no different from those produced by control subjects (Appell, Kertesz and Fisman, 1982; Murdoch, Chenery, 
Wilks and Boyle, 1987; Sanderson, Obler and Albert, 1987).

The strongest evidence for the argument that people with Alzheimer's produce both simple and complex syntactic structures comes from research conducted by Kempler, Curtiss and Jackson (1987). They point out that the syntactic ability of people with Alzheimer's is usually assessed through tests of overall fluency, such as the Western Aphasia Battery. They warn that in these tests, measures of syntactic ability tend to be subjective and are inappropriately linked to lexical and real world knowledge. Their research, which systematically measured syntactic skills in a way that was abstracted away from semantic knowledge, found that the percentage of complex sentence structures produced by Alzheimer's subjects was slightly higher than that of control subjects ( 51 percent for Alzheimer's subjects and 47 percent for control subjects).

The perception of fluency in the language of people with Alzheimer's has also been linked to their tendency toward verbosity. Researchers report that Alzheimer's subjects use more words to convey a single concept (Blanken, Dittman, Haas and Wallasch, 1987; Nicholas, Obler, Albert, Helms-Estabrooks, 1985; Ripich and Terrell, 1988; Sanderson, Obler, Albert, 1987; Smith, Chenery and Murdoch, 1989). For example, Smith et al. counted the number of syllables used to convey a single content unit $^{1}$ and found that subjects with Alzheimer's disease required an average of 12.97

1

The content unit as a measure of conciseness was developed by Yorkston and Beukelman (1980). A content unit is defined as "a grouping of information always expressed as a unit by normal speakers". For example, the sentence "The little boy is on the stool and reaching up for a cookie and he's going to fall over," contains six content units (p. 30). 
syllables per content unit while the control subjects produced an average of 3.88 syllables per content unit.

In another study using the Cookie Theft Picture, Nicholas, Obler, Albert and Helms-Estabrooks (1985) report that Alzheimer's subjects used an average of 103 words to convey 4.8 ideas that were relevant to the picture. The control subjects produced an average of 85 words to convey 6.7 contextually relevant ideas.

Circumlocution and perseveration are primary contributors to the verbose nature of Alzheimer's speech. Alzheimer's subjects commonly circumlocute when they fail to find a correct defining word, and so use more words to convey an idea, (for example identifying a match as a thing you light cigarettes with). To listeners, speech filled with circumlocution may seem wordy and indirect (Ehernberger Hamilton, 1994).

Perseveration, the repetition of sounds, words, phrases or ideas, is also common in the speech of people with Alzheimer's disease (Bayles, 1985; Murdoch, Chenery, Wilks and Boyles, 1987). Bayles reports that repetition of ideas occurs more frequently than repetition of sounds or words. She gives an example of perseveration that occurred in one Alzheimer's subject's description of a marble.

Oh, this is uhm, k-kids used to call 'em mumbly pegs, marble, uh, um, yeah, marbles, an uh, it's used as some sort of a game, used to be called mumbly pegs, that's what they used to call it, but it's sort of orange color, orange that is, yeah, and uh . . . and they use 'em in some sort of game, I think. As I say, they used to call it mumbly peg (p. 170).

As with circumlocution, perseveration makes it appear as though the speaker is conveying more information about a subject than he or she actually is.

This tendency toward verbosity and retention of an intact syntactic system are 
most often cited as reasons why the language of people with Alzheimer's appears fluent. Bayles (1985) sums up these conclusions when she observes that "dementia subjects have the syntactic framework of discourse but little with which to fill it" (p. 165).

Pragmatic Knowledge and Alzheimer's Discourse. The second dominant finding of subject-focused discourse analysis is that certain aspects of pragmatic knowledge are impaired in people with Alzheimer's disease. Both Alzheimer's researchers and caretakers report that when people with Alzheimer's speak, their language is often empty of meaning and irrelevant (Appell, Kertesz and Fisman, 1982; Bayles, 1985; Bayles and Kasniak, 1987; Heller, Dobbs and Rule, 1992; Hier, Hagenlocker and Shindler, 1985; Murdoch, Chenery, Wilks and Boyles, 1987; Nicholas, Obler, Albert and Helm-Estabrooks, 1985; Sanderson, Obler and Albert, 1987). Alzheimer's researchers commonly employ a definition of empty speech developed by Nicholas, Obler, Albert and Helms-Estabrook (1985). "Empty speech consists of words or phrases that either detract from or do not contribute to a coherent description...." (p. 405).

Intact pragmatic knowledge enables a speaker to use language in a manner that is communicatively appropriate and thus comprehensible to the listener. At its narrowest, pragmatic knowledge governs the speaker's use of indexical expressions, such as pronouns and time phrases, that rely on context for their interpretation. More broadly, speakers rely on their pragmatic knowledge to guide their behavior in social interaction. For example, speakers apply pragmatic rules to regulate the flow of conversation and to respond to and ask questions appropriately (Green, 1989). 
Research on pragmatic knowledge and Alzheimer's discourse has focused primarily on identifying specific pragmatic deficits that contribute to the impression that Alzheimer's language is empty. Two deficits that have been extensively researched are the use of indexical expressions without a clear referent and the production of discourse that is irrelevant or noninformative. A third aspect of pragmatic knowledge, speech acts, while receiving less attention among researchers appears to be more intact than the other two.

Several researchers suggest that the empty quality of language produced by people with Alzheimer's is a result of their use of indexical expressions without a clear referent. For example, deictic terms (e.g. this, that, here, there) and indefinite words (e.g. thing, stuff, something) are prevalent in the speech of Alzheimer's subjects (Bayles and Kasniak, 1987; Ehernberger Hamilton, 1994; Nicholas, Obler, Abert, HelmsEstabrook, 1985; Heir, Haganlacker and Shindler, 1985; Sanderson, Obler and Albert, 1987).

Nicholas et al. found that Alzheimer's subjects produced 5.8 deictic terms per 100 words while control subjects produced only 2.4 deictic terms. Indefinite words occurred 1.9 times per 100 words of Alzheimer's subjects but only .7 times per 100 words of control subjects. Hier, Hagenlocker and Shindler (1985) report that Alzheimer's subjects use a greater number of indefinite pronouns. They provide examples of discourse from their study that include both indefinite pronouns and nonspecific words. The discourse was produced by two Alzheimer's subjects when they described the Cookie Theft Picture. The comments made by Hier et al. are included in 
brackets.

-That a kid on something there [fragment, empty word]

-She is dry it. [two empty words]

-Well, this one is drying what she made, drying the stuff [three empty words]

Smith, Chenery and Murdoch (1989) caution that the nameless characters featured in picture description tasks such as the Cookie Theft Picture may inflate the number of indefinite pronouns a subject uses. Furthermore, in ordinary conversation, when the discourse context is narrow and apparent to hearers (as is the case in picture description tasks), speakers often use more non-specific terms (Green, 1989). This tendency might also contribute to the increased use of indexical expressions documented in some Alzheimer's research.

Ripich and Terrell (1988) analyzed discourse produced by Alzheimer's subjects during interviews to determine their appropriate and inappropriate use of structural and semantic cohesive devices. ${ }^{2}$ Alzheimer's and control subjects used an equal number of cohesive devices relative to the total number of words they produced. The Alzheimer's subject's appropriate use of structural cohesive devices was equal to control subjects; however, Alzheimer's subjects produced more than twice as many instances of disrupted semantic cohesion. As was found in other studies of empty speech, Ripich and Terrell found that problems with reference accounted for the greatest number of instances of disrupted cohesion in the discourse of Alzheimer's subjects.

\footnotetext{
${ }^{2}$ Ripich and Terrell define structural cohesive devices as "nonpropositional elements that contribute to the continuity of the discourse but not to continuity of meaning in the text." Semantic cohesive devices included referent defined as "elements whose meaning is present in the text or context;" conjunction defined as "linking elements whose meaning is appropriate to the elements linked;" and ellipsis, "redundant element eliminated but referable from the text or context" (p. 10).
} 
In addition to examining the Alzheimer's subjects' use of indexical expressions, Alzheimer's researchers have studied broader issues of relevancy and informativeness in Alzheimer's discourse. Although there have been no studies that formally analyze Alzheimer's discourse based on Grice's conversational maxims of quality, quantity, relevance and manner, ${ }^{3}$ both researchers and caretakers have noted that the language of people with Alzheimer's is often unintentionally vague, non-informative or irrelevant (Bayles, 1987; Hier, Hagenlacker and Shindler, 1985; Sanderson, Obler and Albert, 1987)

Blanken, Dittman, Haas and Wallasch (1987) evaluated the responses of Alzheimer's subjects to interview questions and found that $60 \%$ of the responses only partially fulfilled or did not fulfill the questions. They classified the inappropriate responses according to ten categories (p. 266). These categories included

Fragmentary: I: When were you born?

P: February 23.

Vague: $\quad$ I: How old are you $\mathrm{Mr}$ (name of patient)?

P: Yes, I don't know-very old-now.

Evasive: I: Where are you now?

P: Uh usually I am am uh longer uh in contact with the old old uh old folks home.

Confabulated: I: Do you know where you are?

$P:$ In in (name of patient's home town).

${ }^{3}$ Grice's Cooperative Principle states that conversational participants will observe four sets of conversational maxims: 1)Quality- Try to make your contribution one that is true; 2) Quantity- Make your contribution as informative as is require (for the current purposes of the exchange); 3) Relation- Be relevant; 4) Manner- Be clear. The power of these maxims is that in assuming that the speaker is either following the conversational maxims, or intentionally violating them, the hearer is able to infer the intended meaning of the speaker's utterance (Green, 1989; Sperber and Wilson, 1986). 
Other contributors to the inconcise nature of their speech is their tendency to repeat words and phrases and to rely on circumlocution. Bayles (1985) cites these factors as reasons for the vague discourse produced by subjects in her studies, pointing out that the Alzheimer's subjects produce fewer units of relevant information when describing objects. The following examples of vague discourse provided by Bayles are drawn from their responses on the Verbal Expressions Test.

E: Tell me everything you can about this (nail).

S: That's for carpentry work. What else will it do? Well, general purpose use in nailing different things, pieces of wood together.

E: Tell me about this (button).

S: This is a button. It can be used in many different ways. It can be sewed on a coat. This button is grayish in color. And, uh, say, it's grayish in color. It's flat. Uh, I've already said it's gray, I think. That's about all. I can't think of anything else.

In their test of functional communication (Communication Ability in Daily Living), Fromm and Holland (1989) found that Alzheimer's subjects responded to questions in "an irrelevant, vague and rambling style" (p. 538). They account for these irrelevant responses by suggesting that Alzheimer's subjects seem to miss the point of questions. For example, in response to one test item which asked "how do you let someone know that you want him or her to stop doing something" (p. 538) a subject with mild Alzheimer's disease responded:

You could find out why they're doing it, and a little bit about how urgent it is that they do it at this moment, and if it's a long thing they're working on, maybe they don't want to be disturbed.

Another subject, in response to a test question which asked them to "calculate how 
much a speeding car should slow down" answered, "Oh that, I don't know that, it all depends on the make of the car" (p. 538).

In Relevance, Sperber and Wilson (1986) state that the relevance of an utterance depends on the set of thoughts the hearer has in his mind at the time the utterance is spoken. They refer to this changing set of thoughts, or premises, as context. The hearer uses his context to interpret the speaker's utterance. Sperber and Wilson point out that the speaker has "no way of controlling exactly which context a hearer will have in mind for a given moment" (p. 119). An utterance will be irrelevant if does not affect the hearer's context by strengthening one of his current assumptions or somehow connecting with the hearer's context in a way that allows him to make an inference about the speaker's intended message.

Thus, the relevance of an utterance, as it is outlined by Sperber and Wilson, depends not only on the speaker, but also on the hearer's context. This suggests that the characterizations of irrelevancy documented by the Alzheimer's researchers mentioned earlier reflect not only the condition of the language produced by the Alzheimer's subjects, but also the condition of the cognitive contexts of the Alzheimer's researchers at the time of their analyses. In their study of coherence and Alzheimer's disease, Ripich and Terrell (1988) do write that judgments of incoherence reflect the listener's intolerance and vary according to the social context and discourse task. Ehernberger Hamilton (1994) warns that discourse elicited via picture and object description tasks may appear irrelevant and non-informative, because the tasks themselves do not allow the subject to say anything new or meaningful to the hearer. 
On the other hand, Ehernberger Hamilton does state that people with Alzheimer's have difficulty assessing the hearer's context and therefore often make erroneous assumptions about how much information the hearer requires. Sperber and Wilson write that it is usually the speaker's responsibility to assess the hearer's context and to attempt to avoid utterances that result in misunderstandings. Issues of speaker and hearer responsibility are further discussed in the following section on interaction analysis.

A final aspect of pragmatic knowledge that has received relatively little attention from researchers is the use of speech acts. Overall, researchers agree that Alzheimer's subjects successfully apply speech acts that are related to common social functions. In their study of communicative language ability, Fromm and Holland (1989) report that speech acts and social conventions such as greetings and accepting apologies were the communicative skills most likely to remain intact in subjects with Alzheimer's disease. Ripich, Vertes, Whitehouse, Fulton and Ekelman, (1991) also report that Alzheimer's subjects' use of most speech act categories, for example responsives (e.g. answering a WH question) and expressives (e.g. exclamations expressing surprise, delight or other attitudes), was comparable to that of the control subjects. Ripich et al. do note that the Alzheimer's subjects produced more requests for information than control subjects. They speculate that the higher number of requestive speech acts reflect the Alzheimer's subjects greater need to gain information about the discourse context as a result of their general cognitive difficulty.

To summarize, researchers who have analyzed subject-focused discourse have 
concluded that people with Alzheimer's retain a great deal of linguistic knowledge but their ability to use that knowledge to communicate is impaired. Specifically, their findings indicate the following about the language abilities of people who have Alzheimer's disease:

1. They have an intact knowledge of syntax until the advanced stages of the disease.

2. Their language is often verbose as a result of circumlocution and perseveration.

3. They often use indexical expressions without a clear referent.

4. They typically convey less information that is directly relevant to the task they have been asked to perform.

5. They have an intact knowledge of speech acts, although they tend to use requestives more often than healthy, age-matched people.

In their effort to determine why some language skills remain intact while others deteriorate, several researchers have proposed that the resiliency of some types of language knowledge over others is linked to how that knowledge is processed cognitively (Appell, Kertesz and Fisman, 1982; Bayles and Kasniak, 1987; Blanken, Dittman, Haas and Wallesch, 1987; Heller, Dobbs and Rule, 199; Murdoch, Chenery, Wilks and Boyle, 1987). In introducing their discussion of Alzheimer's disease and the five subsystems of language (phonology, morphology, syntax, semantics and pragmatics), Bayles and Kasniak (1987) write:

The types of linguistic knowledge vary in their reliance on conscious 
processing, the degree to which they can be automatically applied ${ }^{4}$, and the degree to which they are needed to recover meaning. These three variables can guide the clinician in predicting whether a particular type of linguistic knowledge is likely to be preserved in the dementia patient. Rules that require conscious active processing for their application, and are needed to recover meaning, are those less likely to be preserved (p. 161).

In general, these researchers have asserted that phonology, morphology and syntax are preserved, while semantics and pragmatics are impaired. There is some evidence, however, that within these systems there are differing degrees of preservation or impairment. For example, Kempler, Curtiss and Jackson (1987) write that syntactic sequences vary in the degree to which their processing is cognitively demanding. They note that syntactic sequences that occur frequently and have little variation in their form such as certain conventionalized forms used in social interaction are probably processed more automatically than those sequences that require the integration of novel information. Furthermore, some sequences may contain elements which have little variation, but also require the insertion of new information (e.g. "I'd rather be X-ing" p

The terms "automatic processing" and "automatic language" appear frequently in the research on language and Alzheimer's disease. Bayles and Kasniak (1987) describe automatic language processes as "those which are carried on without conscious processing" (p. 175). Automatic language is less directly defined. Often, the term is used in conjunction with other phrases that suggest less effortful processing. For example, Fromm and Holland (1989) write that Alzheimer's subjects are able to produce language that involves "relatively automatic, overlearned communication behaviors" (p. 537).

In his discussion of automatic and controlled processes, Stillings (1989) writes that when discussing automaticity, one must be clear to distinguish between the technical notion of zero-demand on working memory and a more informal, common use of the term. Complex tasks such as those involved in producing discourse are most likely a combination of controlled and automatic processing, rather than purely automatic. This study assumes that the term "automatic" is being used in its informal sense (e.g. "less effortful") rather than the technical notion of zero-demand on working memory. For additional information concerning the essential characteristics of automaticity in its technical sense, please refer to Stillings (pages $48-60$ ). 
248). They suggest that syntactic breakdown will occur in utterances at the point in which the insertion of new information is necessary.

Recent research also suggests that skills within the pragmatic system are also variously affected. Fromm and Holland propose (1989) that, like syntactic forms, those communicative skills that are more complex and place a greater demand on cognitive processing will suffer greater impairment. In contrast, skills which are overlearned, such as conventionalized language routines and speech acts place less demand on cognitive processing and therefore will remain intact.

\section{Research Based on Interaction Analysis}

A small number of researchers have shifted away from the dominant research trend of focusing on and identifying the language deficits of people with Alzheimer's and have begun to use ethnographic methods to explore the nature of interaction between Alzheimer's subjects and healthy interlocutors. These researchers seem to be motivated in part by a concern that broad conclusions have been drawn about the communicative ability of people with Alzheimer's from a narrow base of data. Interaction analysts maintain that both appropriate and inappropriate use of language can be more clearly understood when considered within a communicative context rather than in isolated, artificially elicited discourse (Bohling, 1991; Crisp, 1993; Ehernberger Hamilton, 1994; Sabat, 1991). In analyzing the language of Alzheimer's subjects, interaction researchers have tried to answer the following questions.

1. Can the eliciting context exacerbate particular language deficits of Alzheimer's 
subjects?

2. Can the communicative behavior of the healthy interlocutor negatively influence the language that is produced by the Alzheimer's subject?

3. In what ways can the healthy interlocutor positively influence the communicative ability of the Alzheimer's subject.

Eliciting Context. Much of the data used in Alzheimer's research have been elicited through controlled test situations rather than natural conversation. Sabat (1991) maintains that language produced within a test situation is different in form and content than language produced in natural conversation. In reference to the Alzheimer's subject in his case study, Sabat writes "there is a world of difference between this Alzheimer's disease sufferer's use of language on test items in testing situations and her use of language for the purpose of a meaningful exchange of ideas" (p. 295).

The Cookie Theft Picture and the Verbal Expressions Test (VET) have been widely used in research on language use. Results from these tests are often cited as examples of the vague and irrelevant discourse that is considered a characteristic feature of Alzheimer's discourse. However, researchers of natural interaction argue that the trivial nature of these tasks seriously limits the range of communicative language knowledge a subject can put to use (Bohling, 1991; Crisp, 1993; Ehernberger Hamilton, 1994; Sabat, 1991). For example, the tasks in the VET involve describing a button, a nail, a marble and an envelope (see page 31). Ehernberger Hamilton cautions that when research on Alzheimer's language uses discourse that has been elicited from such tasks "any resulting conclusions regarding their (Alzheimer's subjects) ability to use language 
to creatively communicate should be carefully considered" (p. 19).

Negative Accommodation. In addition to analyzing discourse that is produced in more natural contexts, researchers who study interaction are interested in understanding the relationship between the interaction behavior of participants and the language they produce. Most Alzheimer's language research has focused on the discourse produced by the subject rather than analyzing the behavior of both participants in the communication context. However, speech does not generally occur in isolation but is the result of a social interaction. Participants interact with one another and their behavior influences the content of the resulting discourse (Cronen, Pearce and Harris, 1982; Goodwin, 1986; Wardhaugh, 1985). Ramanathan Abbot (1994) writes of Alzheimer's research on language:

The focus of such research has been almost exclusively on the resultant narrative rather than the interaction involved in eliciting the narrative. Neglecting to examine the interaction process is a serious exclusion, since narrative is dependent on the reciprocal nature of speaking and listening between the interactants (p. 31).

The potential for the behavior of one participant to negatively influence the behavior of another is particularly strong in the case of people with Alzheimer's disease. Stereotypes of the communicative ability of people with Alzheimer's can lead conversation partners to assume that all utterances made by Alzheimer's subjects will be incoherent (Ehernberger Hamilton, 1994). Assumptions about the behavior of a conversational participant can unintentionally alter their behavior in a self fulfilling manner. Cappella (1985) points out that "when others perceive that a person has a certain quality or trait, they often treat the person accordingly, leading him or her to act 
out the role dictated by the other's perceptions" (p. 402).

Bohling (1991) studied the influence of caregiver listening patterns on the responses uttered by people with Alzheimer's. He found that the turns of Alzheimer's subjects were often reduced to single word utterances when the caregiver controlled the topic of the conversation or did not try to work within the topic frame presented by the Alzheimer's subject.

Ramanathan-Abbott (1994) also analyzed this influence. Two conversations which focused on the subject's life were analyzed, one between the subject (T) and her husband $(\mathrm{N})$ and the other between the subject (T) and Ramanathan-Abbott (R). In the subject's conversation with her husband, her turns consist of short responses to her husband's prompts.

N: What else do you remember about your childhood Tina? You grew up in Peoria

T: Ya [.]

$\mathrm{N}$ : and you mentioned your mother and ah [. .]when you were a small girl there was some problem at that time.

T: What was that Nick?

$\mathrm{N}$ : well you tell me

T: Well my daddy died?

$\mathrm{N}$ : Well that was one, but before that

In contrast, the subject's responses in the conversation with Ramanathan-Abbott are longer and more detailed.

$\mathrm{R}$ : When you look back over your past, Tina, what is it that stands out the most?

$\mathrm{T}$ : Ah [...] well I guess the thing that stands out the most is ah my memories of my illness, and ah the fact that I couldn't even really walk. [. . .] and ah I daddy used to have to carry me, and ah [...] you know. It was a bad situation, but it brought us all close 
together. And ah you see they cut this wound on my back without anesthetic, [.] and I was just a teenager....

As with Bohling, Ramanathan-Abbott concludes that the subject's differing language use is probably not a result of differing ability but a consequence of the behavior of their conversation partner. Ramanathan-Abbott explains that the husband's benevolent assumption that his wife was not able to communicate normally resulted in his overcompensating for her perceived disabilities. As a result, the types of responses that were available to the subject when conversing with her husband were limited. The research of Bohling and Ramanathan-Abbott demonstrates that the language behavior of Alzheimer's subjects can be influenced not only negatively, but also positively by the behavior of their interlocutor.

Positive Accommodation. Ehernberger Hamilton frames the issue of positive and negative accommodation through a discussion of "division of labor" (p. 27). Successful interaction involves a division of labor in which the work required to maintain a coherent, face-saving conversation is divided among the participants. Wardhaugh (1985) writes that participants must make sure that each has the opportunity to share in various aspects of conversation such as selecting topics, providing an appropriate amount of background information and having an adequate opportunity to speak.

In interactions involving a healthy interlocutor and one that is communicatively disabled, the healthy participant must assume a greater portion of the conversational work in an effort to prevent breakdowns in communication (Ehernberger Hamilton, 
1994; Sabat, 1991). If, by shouldering a greater share of the interaction responsibilities, the healthy interlocutor enables his or her conversation partner to participate more actively and the conversation is successfully facilitated, it is positive accommodation. In contrast, if the healthy interlocutor takes on so great a share of the conversational work (over accommodation) that it limits the disabled partner's true ability to participate, it becomes negative accommodation.

Research by Ehernberger Hamilton (1994) and Sabat (1991) provides examples in which the healthy interlocutor assumes a greater share of the division of labor and, in doing so, positively accommodates the participation of the Alzheimer's subject. Ehernberger Hamilton studied the question/response sequences that were produced by herself and an Alzheimer's subject during five conversations that took place over a five year period. When she examined the responses of the subject, Ehernberger Hamilton discovered that the percentage of the subject's responses that were inappropriate did not increase (an average of fifty percent for each conversation) despite her progressively deteriorating language ability. However, there was a qualitative change in the type of inappropriate responses that she produced. For example, responses that were vague accounted for twenty percent of the inappropriate responses in the first conversation but gradually decreased to nine percent in the fourth conversation and zero in the fifth. On the other hand, the number of "no responses" increased.

When she studied the correlation between the types of responses produced by the subject and the corresponding questions asked by Ehernberger Hamilton, she found that the type of questions she was asking had also shifted. For example, the number of 
her WH questions dropped from thirty-six percent to eight percent. Ehernberger Hamilton explains the changing pattern of the question/response sequences in the following way:

Upon closer examination of the data, it appears that in selecting the type of questions to ask her, I was attuning to my preconceptions of Elsie's ability to answer various types of questions. This strategy enabled Elsie despite decreasing abilities to give a high proportion of appropriate responses (p. 124).

As the subject's ability to provide lengthy responses to WH questions decreased, Ehernberger Hamilton posed more Yes/No questions. The subject was still able to participate in the conversations, but her role in responding to questions was reduced to simply confirming or disconfirming the propositions of Yes/No questions presented by Ehernberger Hamilton.

Sabat (1991) recorded and analyzed over thirty conversations between himself and a person with Alzheimer's disease. The subject's speech in these conversations is filled with the perseverations and indefinite terms that are characteristic of Alzheimer's language. Sabat reports that his use of indirect repairs, which consisted mostly of restatements of the subject's ideas, helped to clarify her utterances and facilitated the progression of the conversation. In response to Sabat's repairs, the subject either confirms that Sabat has correctly understood what she was trying to say or she elaborates to provide more information.

Sabat points out that had he not been willing to take on a larger share of the interpretive work in the conversations, the subject's ideas would probably have never become clear. He maintains that in order for healthy interlocutors to positively 
accommodate a person with Alzheimer's, they must be aware of the person's specific linguistic difficulties, but they must also have a desire to understand what the person is trying to say. Interaction analysts such as Sabat have demonstrated that external factors such as the eliciting context and the behavior of the healthy interlocutor can influence the language that is produced by the person with Alzheimer's. Another important contribution of interaction analysis has been to extend the focus of research beyond examining the form and content of specific utterances to an examination of the purpose of utterances within the interaction context. This functional perspective of language forms the content of the final section in this chapter.

\section{LEXICAL PHRASES, FUNCTIONAL LANGUAGE AND ALZHEIMER'S}

\section{Conventionalized Language in Alzheimer's Research}

Researchers of both subject-focused discourse analysis and interaction analysis report that the speech of people with Alzheimer's is filled with conventionalized language patterns (Appell, Fisman and Kertesz, 1982; Bayles and Kasniack, 1987; Crisp, 1993; Ehernberger Hamilton, 1994; Fromm and Holland, 1989; Ripich and Terrell, 1988). Words such as pre-fabricated, language formula, patterned, ready-made, stereotyped, routinized, highly predictable, formulaic and overused all appear in the literature to describe the language of people with Alzheimer's. Other than work by Ehernberger Hamilton, specific examples of conventionalized language are rarely cited by researchers. For example, in their study of functional language Fromm and Holland (1989) simply remark that Alzheimer's subjects use conventionalized language to 
successfully perform routines that involve greetings, accepting apologies and answering questions about personal information.

Most researchers agree that the use of conventionalized language places less demand on cognitive processing and therefore is not effected by the degenerative process of Alzheimer's until late in the disease (Bayles and Kasniak, 1987; Ehernberger Hamilton, 1994; Fromm and Holland, 1989; Kempler, Curtiss and Jackson, 1987). For example, Ehernberger Hamilton found that the conventionalized language used by the Alzheimer's subject in her study was spoken with greater fluency and remained intact longer that the rest of the subject's discourse. For this reason, researchers often describe conventionalized language as automatic.

Researchers of subject-focused discourse generally consider the Alzheimer subject's ability to use conventionalized language patterns of little interest for two reasons. First, language that is processed automatically is not useful for the diagnosis of Alzheimer's because it is less likely to be affected by the disease (Bayles and Kasniak, 1987). Second, some researchers state that exchanges involving conventionalized language do not represent purposeful communication because it can be applied without a great deal of conscious effort. On the other hand, interaction analysts have maintained that the Alzheimer subject's ability to appropriately apply conventionalized language during the correct conversational context is significant. In addition, they have argued that the communicative purpose of such utterances should not be discounted simply because they can be applied automatically.

For example, Crisp (1993) reports that not only does the Alzheimer's subject in 
her work successfully use conventionalized language to engage in greetings and "social chat," but also that on several occasions after exchanging small talk with a staff member in the nursing home, she has remarked to Crisp how important it is "to be pleasant to other people," (p. 66) thus demonstrating that she is aware of the function of the language she is using. Crisp further argues that when determining the degree of communicative purpose of an utterance, researchers should not judge Alzheimer's subjects according to a different set of criteria than those used to judge healthy interlocutors. She points out that healthy interlocutors also use language routines automatically when engaged in conversation; however, their communicative purpose when using such language is not doubted.

A common misperception of conversation is that people create, word by word, all the language they use when interacting with others (Langer, 1978; Tannen, 1989). In fact, conversation is filled with routines that involve specific language patterns (Nattinger and DeCarrico, 1992; Wardhaugh, 1985). Speakers use these patterns for a large part of the conversation they produce, and as a result, the conversations many people believe they are constructing from newly generated language are actually filled with highly predictable language formulas. In addition, as Wardhaugh points out, the purpose of these language routines is primarily to facilitate conversation rather than to impart new information.

There are routines for beginnings and endings of conversations, for leading into topics and for moving from one topic to another. In a few cases routines are so fixed that they have become ritualistic, with formal ways of signaling almost every part of an activity (p. 73). 
While researchers such as Crisp and Ehernberger Hamilton have recognized the importance of their subjects' ability to use conventionalized language, their analysis of the role of this language has been hampered by the lack of a clear framework which connects conventionalized language to specific functions within conversation.

Nattinger and DeCarrico's (1992) discussion of lexical phrases provides a framework for examining not only the functional role of conventionalized language, but also the more general concept of how language functions to facilitate and guide the informational flow of conversational discourse. This section describes Nattinger and DeCarrico's concept of lexical phrases and links it to related Alzheimer's research on memory, language processing and conventionalized language. The first part outlines the concept of lexical phrases and considers how processing features of lexical phrases match the memory and language processing ability of people with Alzheimer's. The second part considers more generally the language functions described by Nattinger and DeCarrico and examines how these functions correspond to descriptions of how people with Alzheimer's use conventionalized language in conversation.

\section{Lexical Phrases}

The connection between Nattinger and DeCarrico's discussion of functional language and the conventionalized language used by people with Alzheimer's begins with the cornerstone of their theory, lexical phrases. Nattinger and DeCarrico define lexical phrases as strings of words that can be analyzed according to syntactic rules and have specific, conventionalized functions in interaction. They do not count all 
grammatical strings of words as lexical phrases, however. Only those strings which are accessed as a chunk and are associated with a particular function in discourse are considered lexical phrases. For example, a speaker can signal a forthcoming opinion by prefacing it with the lexical phrase "I think X." The I think in "I think math is wonderful," or " think you are crazy" is a pre-assembled chunk of language that serves a specific function; to assert an opinion. On the other hand, the I think in "I think about chocolate morning, noon and night," or "I think best when there's music playing" are generated via syntactic rules and have no conventionalized function.

In addition to distinguishing between lexical phrases and syntactic strings, Nattinger and DeCarrico also distinguish lexical phrases from other conventionalized forms of language such as idioms (e.g. kick the bucket), clichés (e.g. a good time was had by all), and collocations (e.g. salt and pepper). Like lexical phrases, these multiword phrases are generally accessed as a chunk. However, unlike lexical phrases, they do not consistently serve a set function in discourse such as signalling a topic shift or expressing disagreement.

Nattinger and DeCarrico describe lexcial phrases as lexico-grammatical units. They are considered a part of the lexicon because they behave much like other items in the lexicon. Unlike words, however, lexical phrases can be analyzed according to syntactic rules.

As form function composites, lexical phrases are also a part of the knowledge of principles that guide one's use of language (pragmatic competence). People draw on lexical phrases to signal particular functions in discourse. For example, lexical phrases 
are used to introduce a topic, to signal disagreement and to summarize a preceding idea. About this combined pragmatic and grammatical identity of lexical phrases, they write

Thus, although grammatical competence encompasses the knowledge of lexical forms and their internal syntax, pragmatic competence accounts for the speaker's ability to continue to access these forms as preassembled chunks, ready for a given functional use in an appropriate context (p. 13).

Finally, Nattinger and DeCarrico suggest that lexical phrases increase the efficiency with which language is processed and therefore contribute to a person's ability to speak fluently. Working memory can process only a limited number of chunks of information. Information that is conventionally associated as a unit is processed as a single chunk (Schneider and Shiffrin, 1977; Stillings, 1989). For example, the string of letters FBI would be processed as a single chunk of information. However, the same letters would be processed as three separate chunks if the string were IBF. Nattinger and DeCarrico maintain that because the words in lexical phrases are associated as a unit, they can be retrieved and processed as a single chunk of information and therefore may place less demand on cognitive processing.

In sum, lexical phrases are conventionalized chunks of language that provide a frame into which conversational content can be inserted. These frames signal specific conversational functions. While not all functions that occur in discourse are carried out via lexical phrases, their frequency within conversations suggests that lexical phrases are an important tool in facilitating and forming the functional scaffolding of conversation. 


\section{Lexical Phrases and Alzheimer's Research}

Three findings concerning memory and language processing in Alzheimer's research support the existence of an intact system of lexical phrases in people who have Alzheimer's disease. First, research on memory and Alzheimer's disease suggests that salient information established by repetition over a long period of time is more likely to remain intact (Jorm, 1987; Morris and Kopelman, 1986). Lexical phrases, as conventionalized sequences of language, fit this description. Because they serve essential functions within conversation, they are frequently and consistently used over the course of one's lifetime, and thus are likely to form a well established set of knowledge.

Second, Alzheimer's memory research states that people have a limited capacity to perform several independent tasks simultaneously. The higher the demand a task places on the central executive system, the less capable the CES is of successfully processing it. People with Alzheimer's reach their processing limit more quickly than healthy people, because the disease impairs the functioning ability of the CES (Morris, 1994). Nattinger and DeCarrico suggest that because lexical phrases form a single unit of information, they can be more easily processed. If this is true, processing lexical phrases would place less demand on the CES and therefore be processed more successfully than phrases which are generated via syntactic rules.

A third piece of supporting evidence comes from Kempler, Curtiss and Jackson's (1987) work on syntax and Alzheimer's language. Kempler et al. examined the relationship between how syntactic sequences are formed and the syntactic errors 
produced by people with Alzheimer's. They state that some syntactic sequences are more fixed than others. Furthermore, in sentences produced by Alzheimer's subjects that combine fixed syntactic sequences with novel information, the fixed sequence will remain intact while the novel information will contain errors.

We should expect maintenance of those aspects of grammatical production that do not require integration of novelty. Also, we should see errors in those instances that do require the integration of controlled processing (p. 349).

Lexical phrases, as chunks of conventionalized language, correspond to Kempler et al's. description of fixed syntactic sequences. For example, one common form of lexical phrase is the sentence builder, which occurs at the beginning of an utterance and frames the sentence content (e.g. "I'd like to X"). This form of lexical phrase is functionally identical to Kempler et al.'s example, "I'd rather be X-ing."

Thus, several characteristics of lexical phrases conform to the specific memory and language processing requirements of people with Alzheimer's. First, they constitute well established, salient pieces of information in memory. Second, they are processed more easily. Third, they conform to patterns of syntactic frames that remain intact longer than the novel information that is inserted into these frames. This parallel suggests that people with Alzheimer's might retain use of lexical phrases longer than other forms of language knowledge.

\section{Language Functions and Lexical Phrases}

Nattinger and DeCarrico's concept of lexical phrases provides a theoretical definition of the conventionalized language described in Alzheimer's research. It also 
links conventionalized language to the notion that language can have a functional as well as an informative role in conversation. When involved in conversation, a speaker must manipulate several layers of knowledge simultaneously (e.g. linguistic and world knowledge). Functional language is a metacommunicative layer of knowledge that shapes and frames the discourse produced by speakers. Exchanging greetings and accepting apologies are two of the common functions of conventionalized language mentioned in the literature on Alzheimer's (Appell, Fisman and Kertesz, 1982; Bayles and Kasniak, 1987; Crisp, 1992; Fromm and Holland, 1988). However, these two functions represent only a small number of the functions necessary to sustain a conversation. Nattinger and DeCarrico describe three types of language functions that are relevant to this study: Conversational Maintenance, Conversational Purpose and Necessary Topics. Each of these categories contain a set of conventionalized language (lexical phrases) that are commonly (although not always) used by speakers to execute the three types of functions.

Conversational Maintenance. The category of Conversational Maintenance involves language that is used to maintain and direct the flow of conversation. For example, two speakers conventionally open conversation by a summons and response to the summons (Schegloff, 1968). To maintain the conversation, speakers must also ask for clarification when the content of the conversation becomes unclear. Examples of the lexical phrases associated with these functions appear in Table 1. 


\begin{tabular}{|c|c|}
\hline Function & Lexical Phrase \\
\hline Summoning & $\begin{array}{l}\text { excuse me/pardon me } \\
\text { hey/hi, (Name), how are you? }\end{array}$ \\
\hline Responding to summons & $\begin{array}{l}\text { hi/hello, (name) } \\
\text { (I'm) fine, thanks, (and you)? }\end{array}$ \\
\hline Clarifying: audience & what did you mean? \\
\hline
\end{tabular}

Conversational Purpose. The category of Conversational Purpose involves language which provides clues to the speaker's intended purpose of particular utterances. For example, speakers use functional language to frame compliments, to indicate that they agree with the previous speaker's comment and to request information or help. Table 2 gives examples of the lexical phrases associated with these functions.

\begin{tabular}{|c|c|}
\hline Function & Lexical Phrase \\
\hline Complimenting & $\begin{array}{l}\text { NP + BE/LOOK + (intensifier) + Adj. } \\
\text { (e.g. "You look wonderful") }\end{array}$ \\
\hline Responding: endorsing & I absolutely/certainly/completely agree \\
\hline Requesting & $\begin{array}{l}\text { Modal + Pro + VP (i.e. may/can I help } \\
\text { (you)?) }\end{array}$ \\
\hline
\end{tabular}

Necessary Topics. Conversational Maintenance and Conversational Purpose help to create order in the flow of discourse. The patterns established by the types of functions render conversations predictable rather than chaotic. The functional language 
of Necessary Topics is not as closely involved in policing the flow of discourse. Its primary role is to signal topics which are commonly discussed in social interaction. Examples of these topics are included in Table 3.

\begin{tabular}{||l|l||}
\hline \multicolumn{2}{|c|}{ Table 3. Necessary Topics and Associated Lexical Phrases } \\
\hline \multicolumn{1}{|c|}{ Function } & \multicolumn{1}{|c|}{ Lexical Phrase } \\
\hline \hline Autobiography & my name is_; I'm from \\
\hline Time & when is X? the_before/after \\
\hline Likes & Ilike/enjoy_(a lot $) ;$ I'd like to $X$ \\
\hline
\end{tabular}

Thus, functional language influences conversation in two ways. First, it establishes a framework within which speakers conduct their conversation. Second, speakers often combine lexical phrases, as conventionalized forms of functional language with the phrases they create from scratch to express their ideas and facilitate conversation. Nattinger and DeCarrico (p. 72) provide a conversation with labels which show how functional language works in a typical interaction. Underlined portions of the sentences indicate lexical phrases. CM refers to Conversational Maintenance. CP refers to Conversational Purpose, and NT refers to Necessary Topics (DD refers to discourse devices which are described in Lexical Phrases and Language Teaching on pages $64-65$, but not included in this study).
A: Excuse me? (sustained intonation) (summons: $\mathrm{CM}$ )
B: Yes, mav I help you? (response: $\mathrm{CP}$ )
A: Can you tell me where the Saturday Market is please? (request: CP) (location: NT)
B: I'm not sure but I think (assertion: CP) (evaluator: DD) (fluency device: DD) it's three blocks over, next to the Burnside Bridge. (location: NT)
A: Pardon me the Burnside Bridge? (audience clarification: $\mathrm{CM}$ ) 
B: It's just three blocks to your right. (location: NT) You can't miss it.

A: $O K$ well (closing: $\mathrm{CM}$ ) thanks very much. (politeness: $\mathrm{CP}$ )

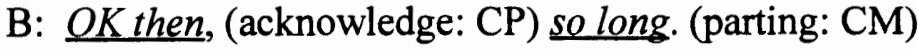

Evidence for an intact ability of people with Alzheimer's to use functional language within conversation comes from the correspondence between descriptions of how conventionalized language is used by people with Alzheimer's and the functional categories described by Nattinger and DeCarrico. In her research of natural interactions between an Alzheimer's subject and a healthy interlocutor, Ehernberger Hamilton (1994) supplies the largest number of examples of conventionalized language in the Alzheimer's literature. Her descriptions of the functional roles of this language correspond closely to Nattinger and DeCarrico's categories of Conversational Maintenance and Conversational Purpose.

The first category of conventionalized language described by Ehernberger Hamilton involves language that "performs procedural tasks within conversation" ( $\mathrm{p}$. 61). Two examples of these procedural tasks are "attention getting devices" (p. 61) and "phrases that are used to indicate that an utterance was not heard" (p. 62). These functions are consistent with Nattinger and DeCarrico's Conversational Maintenance functions. Table 4 compares two of Ehernerger Hamilton's examples conventionalized language that performs procedural functions with the corresponding lexical phrases that function to maintain conversation. 


\begin{tabular}{||l|l|l|l||}
\hline \multicolumn{2}{||c|}{ Table 4. Comparison of Conversational Maintenance and Procedural Tasks } \\
\hline $\begin{array}{c}\text { Conversational } \\
\text { Maintenance } \\
\text { (Nattinger \& DeCarrico) }\end{array}$ & Example & $\begin{array}{c}\text { Procedural Tasks } \\
\text { (Ehernberher Hamilton) }\end{array}$ & \multicolumn{1}{|c|}{ Example } \\
\hline \hline 1. Summons & "hey, (NAME)" & $\begin{array}{l}\text { Attention getting } \\
\text { device }\end{array}$ & "listen, dear honey" \\
\hline $\begin{array}{l}\text { 2. Clarifying: } \\
\text { audience }\end{array}$ & $\begin{array}{l}\text { "what did you } \\
\text { mean by X?" }\end{array}$ & $\begin{array}{l}\text { Indicate utterance } \\
\text { was not heard }\end{array}$ & $\begin{array}{l}\text { "what did you say, } \\
\text { honey?" }\end{array}$ \\
\hline
\end{tabular}

Ehernberger Hamilton also describes several types of conventionalized language that have functions that are similar to Nattinger and DeCarrico's category of Conversational Purpose. For example, Ehernberger Hamilton states that her subject used conventionalized language to (1) respond to the speaker's previous utterance and (2) establish her relationship to the content of an utterance. Table 5 compares these conventionalized language forms, as well as two others described by Ehernberger Hamilton that have functions similar to Nattinger and DeCarrico's Conversational Purpose lexical phrases. Ehernberger Hamilton's term for each of the four categories of conventionalized language have been included. 


\begin{tabular}{|c|c|c|c|}
\hline \multicolumn{4}{|c|}{$\begin{array}{l}\text { Table 5. Comparison of Conversational Purpose Lexical Phrases and } \\
\text { Conventional Language Described by Ehernberger Hamilton }\end{array}$} \\
\hline $\begin{array}{c}\text { Conversational } \\
\text { Purpose } \\
\text { (Nattinger \& DeCarrico) }\end{array}$ & Example & $\begin{array}{c}\text { Conventionalized } \\
\text { Language } \\
\text { (Ehernberher Hamilton) }\end{array}$ & Example \\
\hline 1. Response:endorse & $\begin{array}{l}\text { "I absolutely } \\
\text { agree" }\end{array}$ & Linguistic formula & $\begin{array}{l}\text { "I should say } \\
\text { so" }\end{array}$ \\
\hline 2. Response:disagree & "I don't agree" & Metacommunicative & "I doubt" \\
\hline 3. Complimenting & $\begin{array}{l}\mathrm{NP}+\mathrm{BE}+ \\
\text { intensifier + adj. }\end{array}$ & Complimenting & $\begin{array}{l}\text { "Your hair is } \\
\text { so beautiful." }\end{array}$ \\
\hline $\begin{array}{l}\text { 4. Expressing } \\
\text { gratitude }\end{array}$ & "thanks" & $\begin{array}{l}\text { Expressions of } \\
\text { appreciation }\end{array}$ & $\begin{array}{l}\text { "All right, } \\
\text { thanks" }\end{array}$ \\
\hline
\end{tabular}

The close correspondence between Ehernberger Hamilton's descriptions of conventionalized language and the functional categories outlined by Nattinger and DeCarrico is further evidence that people with Alzheimer's disease retain an ability to use functional language to facilitate conversation. Moreover, it appears that the conventionalized language frequently mentioned by Alzheimer's researchers is similar in form and function to the lexical phrases described by Nattinger and DeCarrico.

\section{CONCLUSION}

The primary focus of research on Alzheimer's disease over the past twenty years has been to document the type and progression of language degeneration experienced by people with Alzheimer's disease. This focus has been motivated by the need both to distinguish Alzheimer's disease from other types of disease that involve aphasia and to use language as a diagnostic tool for determining the stage of individual patients in the 
course of the disease. Only recently have researchers begun to examine the communicative use of language by people with Alzheimer's within the context of natural interaction. These researchers have argued that the artificial contexts often used to elicit discourse, as well as the negative accommodation of interlocutors can exacerbate the apparent language difficulties of Alzheimer's subjects.

Other than work by Fromm and Holland (1988) there has been no research which directly assesses the use of functional language by people with Alzheimer's. Moreover, the research of Fromm and Holland does not provide a satisfactory account of functional language use. First, it examines discourse that is elicited via a test rather than natural communication, which subjects it to the risks pointed out by interaction analysts. Second, because the functional skills are examined as isolated items on a test, the results do not capture the broader use of functional language to maintain and move conversation forward. Ehernberger Hamilton indirectly discusses functional language in her examination of her subject's use of automatic language. However, her primary focus of interest is the formulaic and fluent nature of this language and its implications for language processing rather than how the subject uses functional language in conversation.

Nattinger and DeCarrico's work defining lexical phrases as a conventionalized form of functional language helps clarify past research on conventionalized language as well as exposing gaps in the current discussion of functional language. This review of the relationships among Alzheimer's disease, language use and lexical phrases, suggests that research on functional language use within the context of natural interaction would 
provide useful information not currently available concerning how people with Alzheimer's disease use functional language to communicate within conversations. 


\section{CHAPTER III}

\section{RESEARCH DESIGN}

\section{INTERACTION ANALYSIS}

The approach selected to conduct research must serve the goals of the research project. This study, an examination of how a person with Alzheimer's disease uses language to communicate with others was based primarily on interaction analysis. This research method, a subset of discourse analysis, examines the relationship between utterances produced by all participants within an interaction setting. Interaction analysis presents several advantages over other research methods that have been used in the past to study the language of people with Alzheimer's disease.

First, very few studies of Alzheimer's language have been conducted at the interaction level. Instead, the strategies of past Alzheimer's research have focused primarily on individual word and sentence level production. These methods have revealed significant information about lexical difficulty, syntactic knowledge and specific, sentence level language deficits; however, they have not been as effective in describing how people with Alzheimer's use language to communicate. Additional research at the interaction level, can help fill this current gap in Alzheimer's language research. The interaction analysis in this study centers on natural conversations between 
a person with Alzheimer's disease and a healthy interlocutor. It examines how both the subject and the interlocutor use and respond to language in the process of carrying on a conversation.

Second, the broad, contextual focus of interaction analysis enables researchers to examine the metacommunicative functions of language to account for the presence of utterances that do not appear to have a purely informative function. In the underlined section in the example below, from Ehernberger Hamilton (1994), a sentence level analysis would do little beyond note that the subject repeated a phrase. By contrast, an interaction analysis reveals that the repetition served a particular function within the conversation. Ehernberger Hamilton uses this excerpt to demonstrate the subject's (Elsie) ability to handle the structural mechanics of turn-taking. She remarks that the subject is aware that she must repeat her utterance because it was overlapped by the interlocutor's utterance. She also notes that the Alzheimer's subject was able to complete her own idea (so we fixed them up) while simultaneously attending to the question of the interlocutor (Well, what is this?).

Heidi: Those are more flowers.

Elsie: Yes. Uh huh. Aren't they darling?

Heidi: $\quad$ Yes Well what $=$

Elsie.

So we

Heidi: is this?

Elsie: So we, fixed em up. We fixed em up Well, there I am and my $=$

Heidi: uh huh

Elsie: =husband.

(Ehernberger Hamilton, 1994; p 64)

The interaction analysis goes beyond simply counting the presence or absence of 
particular language behaviors to examine the communicative function of language within the context of the interaction.

Third, interaction analysis considers the discourse of both the Alzheimer's subject and the healthy interlocutor. This dual focus provides a more balanced perspective of the language produced by the Alzheimer's subject as well as enabling the researcher to examine how both conversational participants influence one another's language. Two common strategies of past Alzheimer's research have been to examine only the language produced by the Alzheimer's subject and to identify deficits within Alzheimer's language. When these two strategies are combined, language behaviors that might be overlooked if produced by a healthy speaker are judged as deficient when produced by the Alzheimer's subject (Crisp, 1993; Ehernberger Hamilton, 1994). For example, as evidence of the pragmatic deficits experienced by subjects with Alzheimer's, Blanken, Dittman, Haas and Wallasch (1987) report that the majority of the subjects' did not adequately respond to questions in an interview. Among their examples of inadequate responses were sentence fragments and "vague" (p. 266) answers. However, answers of this sort also occur in the discourse of healthy conversants. Green (1989) writes that most verbal utterances are vague and require some degree of interpretation by the listener.

Interaction analysis not only reduces the likelihood of judging the Alzheimer's subject by different criteria than the healthy interlocutor, but also examines how potentially atypical language behavior is handled by the conversational participants and its effect within the context of the interaction. Furthermore, Ehernberger Hamilton 
suggests that when atypical language patterns appear, the researcher should consider what influence the healthy interlocutor or eliciting situation might have had on the subject's language production.

For example, Ripich and Terrell (1988) found that during conversations between a researcher and an Alzheimer's subject, both participants produced fewer words per utterance than occurred in conversations between the same researcher and control subjects. Ripich and Terrell speculate that the shorter turns might reflect the memory difficulties of the Alzheimer's subjects. However, Ehernberger Hamilton notes that it is just as likely that the Alzheimer's subjects, rather than initiating the pattern of short utterances were actually following the pattern set by the researchers, who had prejudged how much language the Alzheimer's subjects would be able to understand in a single utterance.

Because the goal of this study is to learn how language is used by a person with Alzheimer's disease in conversation, interaction analysis is combined with an emphasis on describing language in use rather than identifying language deficits. A case study involving one person with Alzheimer's disease conversing with three different interlocutors forms the core of this thesis. Focusing on a single subject enables the researcher to discover consistent patterns of language use that occur over a period of time with a variety of interlocutors. 


\section{DATA COLLECTION}

A total of eight conversations were recorded from January, 1994 to August, 1994. These dates were chosen randomly based on the convenience of the interlocutors who recorded the conversation. Each conversation was transcribed by the researcher immediately after it was recorded. Each utterance was transcribed as closely as possible to the original recording and comments concerning gestures, intonation and facial expressions that are significant to the meaning of the utterance were included in brackets next to the utterance (see Appendix B for further information about transcription symbols). The recordings and transcripts were reviewed and edited by the researcher a second and third time in January, 1995 and April, 1995 in order to ensure the accuracy of the transcripts.

All of the conversations were recorded in the Alzheimer's wing of a large nursing home. The subject had lived in this unit two years prior to the recording of the conversations. She is allowed to leave the unit when accompanied by a visiting friend or relative; however, because the environment outside the Alzheimer's unit is confusing and stressful for her, she rarely leaves. During 1994, the subject did not leave the Alzheimer's unit more than ten times. The unit is equipped with two small kitchens and two small sitting rooms in addition to each resident's bedroom which they share with another resident.

The majority of conversations occurred on a sofa or chair in the hallway where the subject likes to sit and watch the activities of other people in the unit. Conversations 
were also recorded in the kitchen and in the subject's bedroom. Each conversation is summarized below.

CONVERSATION ONE January, 1994 (seventeen minutes).

The primary participants in this conversation include the subject (Tillie), the subject's husband (John), and the researcher (Julie). When the conversation opens, Tillie is sitting in the kitchen area with several residents listening to Christmas music. As she notices John and Julie, she approaches them singing and holding her arms out. The bulk of the conversation takes place on a sofa which is near the kitchen and the nurses' station. Tillie is in a very light and sociable mood during entire the conversation and the talk centers on people and daily activities.

CONVERSATION TWO February, 1994 (fourteen minutes)

The primary participants are Tillie (the subject), John (the subject's husband), and Julie (the researcher). A conversation lasting two minutes also occurs between three residents in the Alzheimer's unit. These participants are Fred, Tim and Lucy. Several nursing attendants are also involved. Tillie is sleeping in a chair across from the nurses' station when Julie and John approach her. Unlike conversation one in which Tillie and Julie carry most of the conversation, John plays a greater role in conversation two. Topics include Tillie's work as a nurse, entertaining guests and commenting on people in the Alzheimer's unit.

\section{CONVERSATION THREE July, 1994 (eight minutes)}

The primary participants are Tillie and Julie. Tillie is standing next to the nurse's station with several attendants when the conversation opens. Tillie's hair has recently been styled and this is the topic for the first portion of the conversation. Although Julie makes several attempts to have Tillie join her in a chair in the hallway, Tillie is distracted by the long metal handle of a nearby door. Of the eight conversations, Tillie is the least socially involved in this conversation. After the initial discussion of her hair, remains distracted throughout the rest of the conversation.

\section{CONVERSATION FOUR July, 1994 (eight minutes)}

The primary participants are Tillie and Julie. As the conversation opens, Tillie is talking to an attendant who is mopping the floor in the hallway. It is midafternoon and the Alzheimer's unit is very quiet. The conversation takes place in one of the small kitchens and Tillie's mood is happy and sociable. The central topic of this conversation is Tillie's mother (long dead) who Tillie says is ill. Interestingly, several days earlier, Tillie's daughter had taken Tillie to see her husband John, who is critically ill in the hospital wing of the nursing home. 
CONVERSATION FIVE August, 1994 (eleven minutes)

The primary participants are Tillie and Debi, her primary caretaker. The conversation takes place in Tillie's room at 9:00 pm. With Debi's help, Tillie is getting ready for bed. Tillie's mood is happy and she discusses several topics such as her husband's dentures, the pain in her knee and work she needs to finish at home. Although Debi tries to get Tillie to go to sleep, Tillie insists that she is not sleepy and eventually she gets up, puts on her slippers and leaves her bedroom.

CONVERSATION SIX August, 1994 (twelve minutes)

The primary participants are Tillie and Debi. As the conversation opens, it is evening and they are entering Tillie's bedroom. During the first twelve utterances, Tillie is very angry; however, Debi calms her and the anger subsides. Throughout the rest of the conversation, Tillie's mood is happy. In addition to the discussion involved in dressing Tillie for bed and brushing her teeth, Tillie complains that her hair looks flat. They discuss her hair for several minutes as Debi brushes it.

\section{CONVERSATION SEVEN August, 1994 (fifteen minutes)}

The primary participants are Tillie and Marie, Tillie's daughter. Marie brings a scrap book about the town in which Tillie was born. It was published when Tillie was young and includes photographs of Tillie, her friends and her father's shop. Marie makes several attempts to engage Tillie in a conversation about the book, but Tillie does not respond. Tillie nominates several topics and on several occasions mentions that she is tired and wants to go home.

\section{CONVERSATION EIGHT August, 1994 (eleven minutes)}

The primary participants are Tillie and Marie. Tillie is sitting in a room sleeping at a chair and wakes up when Marie approaches her. Tillie is in a sociable mood in this conversation; however, her discourse is the most unclear of the eight conversations and Marie has difficulty following Tillie's topic nominations. Although it might appear that these last two conversations are evidence that Tillie's language deteriorates during the eight months in which the conversations were recorded, this is not the case. Tillie's language continues to fluctuate between lucidity and incoherence in conversations that occur after August, 1994.

\section{RESEARCH SUBJECTS}

The primary subject in this study is an eighty-five year old woman with Alzheimer's disease. The subject was first diagnosed with Alzheimer's in 1988; 
however, relatives had begun to notice symptoms of the disease in 1986, two years before her official diagnosis. Therefore, when the data was collected for this study, the subject had had Alzheimer's disease for at least seven years and perhaps for as many as eight or nine years. The typical life span of a person with Alzheimer's disease is eight to twelve years after the onset of the disease (Beck, 1991).

When asked for a general assessment of the subject's language ability, the supervisor of the Alzheimer's unit where the subject lives stated that her language skills were lower than many of the other residents. On the other hand, the supervisor remarked that the subject was still very capable of communicating her needs to the staff.

Three other people were also involved in this research. These people were selected because they had a close relationship with the subject prior to the study. This pre-existing relationship meant that a natural rapport already existed between the subject and her interlocutors. This was necessary to ensure that the recorded conversations involved natural interaction rather than artificially created interactions among strangers. Each of the eight conversations recorded for this study is typical of the conversations the subject has had with these interlocutors on many occasions both before and after the recording period of this research project.

The subject's interlocutor in the first four conversations is myself. Tillie has been a close family friend for most of my life. I often visited Tillie and her husband in their home two or three times a year. My life long relationship with Tillie has enabled me to recognize characteristics of her speech that were present before the onset of Alzheimer's, as well as allowing me to observe changes. In addition, my familiarity 
with Tillie's background has helped me decipher her comments and understand particular references she makes during the conversations. Although the tone of our conversations is friendly and informal, Tillie no longer knows who I am or how I am related to her life.

The second interlocutor is Debi. Debi has worked as a certified nursing assistent for several years in the Alzheimer's unit where Tillie lives. She is responsible for bathing and dressing Tillie as well as attending to her when she is ill and looking after her general well-being. Tillie appears to recognize Debi more often than other attendants or friends and relations and she often addresses her with terms of endearment. The third interlocutor is Marie, who is Tillie's first daughter. They have lived in the same town for 19 years and visited one another frequently before Tillie moved into the Alzheimer's unit. Although Tillie no longer realizes that Marie is her daughter, her face still registers a recognition of someone special or important when Marie visits her.

To a lesser degree, several other people are involved in the conversations. These include the subject's husband, other residents in the Alzheimer's unit and several attendants and nurses. To protect the identity of the primary subject and the interlocutors, (other than myself) as well as other people who are mentioned in the transcripts, all names have been changed. In addition, names of locations mentioned in the transcript have also been changed. 


\section{TREATMENT OF THE DATA}

The analysis of the data occurred in three stages. First, the subject's language was examined to develop a profile of basic language skills that remain intact and those that are impaired. This analysis is primarily quantitative and includes two sections. First, several basic skills required to participate in conversation such as turn-taking, producing extended discourse and nominating and responding to new topics are examined. Based on past Alzheimer's research on language deficits, four aspects of language were then analyzed to determine the degree of the subject's language impairment. These include the subject's use of pronouns, nonspecific words, neologisms (created words) and self repetition.

Next, the utterances of both the subject and her three primary interlocutors was examined with an emphasis on exploring each participants' functional use of language within the conversations. The conversations are analyzed according to three categories of functional language which are commonly present in social interactions. The categories are drawn from Nattinger and DeCarrico's (1994; p 60-63) work on lexical phrases and include the following.

Conversational Maintenance (language that is used to direct the flow of conversations)

SUMMONING

RESPONDING TO

SUMMONS

NOMINATING

A TOPIC
"Hi/hello (NAME)" "How are you doing?"

"Hi" "What's going on?" "Fine"

"What's X?" "Do you know X?"

"Have you heard about X?" 
SHIFTING

A TOPIC

CLARIFYING

audience

speaker

CLOSING

PARTING "(say,) by the way" "oh, that's reminds of X"

"What did you mean by X?" "You mean?"

"What I mean is X." "I said X"

"(it's been) nice talking to you"

"see you later" "good bye"

Conversational Purpose (language that provides clues to the speaker's intended purpose of a particular utterance)

EXPRESSING POLITENESS

QUESTIONING

ANSWERING

REQUESTING

OFFERING

COMPLYING

REFUSING

COMPLIMENTING

ASSERTING

RESPONDING

reinforcing

accepting

endorsing "thanks (very much)"

"do you X?" "is/are there/it/they X?"

"yes (there/they is/are) (X)"

MODAL + PRO + VP, "may I X?"

MODAL + PRO + VP,"would you like $\mathrm{X}$ ?"

"of course" "sure (thing)"

"of course not" "no way"

"NP + BE/LOOK + ADJ "You look wonderful"

"I think/believe that X"

"(and then) what happened" "(oh,) I see" "(yeah), I know"

"yes, that's so/correct/right" "that's great" 
EXPRESSING

GRATITUDE

EXPRESSING

SYMPATHY "thanks (very much) (for X)"

"I'm (very) sorry about X"

Familiar Topics (language that is associated with common topics of discussion in social interaction) ${ }^{1}$

\section{AUTOBIOGRAPHY}

QUANTITY

TIME

LOCATION

WEATHER

LIKES

$\mathrm{X} "$

FOOD

SHOPPING
"My name is X"

"(not) a great deal" "lots of X"

"a X ago" "the X before"

"where is X?" "across from X"

"it's very $\mathrm{X}$ today!" "I'm X"

"I like/enjoy X (a lot)" "I'd like to

"I'd like (to have) X"

"how much is X?" "a (really) good/bad buy/bargin"

Nattinger and DeCarrico point out that this list of functional language categories is not an exhaustive one, nor are the listed examples of lexical phrases associated with each function.

In summary, the design of this research project is based on interaction analysis. This method was selected as the most effective means of examining the use of of functional language. 
functional language by a person with Alzheimer's disease and her healthy interlocutors. Eight naturally occurring conversations between the subject who has Alzheimer's disease and three people familiar to the subject were recorded and form the core of this thesis. First the subject's language was examined to develop a profile of basic language skills that remain intact and those that are impaired. Next, the conversations were analyzed according to three categories of functional language outlined by Nattinger and DeCarrico in their work on lexical phrases to determine the subject's ability to use and respond to functional language. 


\section{CHAPTER IV}

\section{RESEARCH FINDINGS}

\section{INTRODUCTION}

The goal of this study is to examine the language produced by a person with Alzheimer's disease to determine what communicative skills remain intact that enable her to maintain conversational fluency despite lexical and pragmatic deficits. Research on language and Alzheimer's disease, particularly research based on subject-focused discourse analysis is rather pessimistic about the ability of people with Alzheimer's to successfully participate in conversation. Bayles and Kasniak (1987) write:

The many anecdotal reports of dementia patients having difficulty maintaining the topic, taking turns, being insensitive to others in the conversation, saying either too much or too little, and failing to repair misunderstandings suggest that many aspects of conversational ability are affected (p. 175).

By contrast this study has found that, while the subject has several serious linguistic deficits, she has also retained skills that are necessary to participate actively in each conversation. Chapter one posited that the framework or scaffolding which holds conversations together seems to have remained intact in the subject's speech even 
though the content of her conversations is often unclear or implausible. When language functions are separated from the content of conversations, it becomes evident that the subject can still manipulate the functional language which forms this scaffolding.

Central to this conclusion was the research approach used in the study. Eight naturally occurring interactions between the subject and three healthy interlocutors were recorded and transcribed. The transcripts were then analyzed in three stages. First, the subject's language was profiled, and basic language skills that remain intact were distinguished from those that are impaired. Next, the subject's and her three primary interlocutors' utterances were categorized according to three types of functional language drawn from Nattinger and DeCarrico's (1992) work on lexical phrases: (1) conversational maintenance; (2) conversational purpose; and (3) familiar topics. Four questions guided the analysis:

1. Does the subject use or respond to functional language that guides or maintains the flow of conversation?

2. Does the subject use or respond to functional language that provides clues to the speaker's intended purpose of a particular utterance?

3. Does the subject use functional language to discuss familiar topics?

4. What role do lexical phrases play in facilitating the subject's use of functional language?

This chapter has four sections. First, it discusses the subject's basic language skills in order to profile her abilities and deficits relative to the findings of past 
Alzheimer's research. Second, both the subject and her interlocutors' use of functional language to maintain conversations is examined. The third section discusses how the subject and her interlocutors signal the conversational purpose of particular utterances, and finally the functional language that is used by the subject to discuss familiar topics is examined.

\section{LANGUAGE PROFILE}

This profile provides a sketch of Tillie's basic language skills in six areas at the time this study was conducted. An examination of basic skills required to participate in conversations such as turn-taking, producing extended discourse and nominating and responding to new topics suggest that Tillie has not yet arrived at an advanced stage of the disease. On the other hand, Tillie does experience a great deal of lexical difficulty. She produces pronouns without a clear referent, uses empty words and discusses vague or implausible topics. Together, these characteristics suggests that she has progressed beyond the early or mild stage of Alzheimer's. This section discusses Tillie's language ability in each area.

First, Tillie has retained her ability to shift and maintain turns at appropriate intervals. This allows her to produce utterances equal in number to the primary interlocutors. Table one compares the number of utterances produced by Tillie, her primary interlocutors and other participants in each of the eight conversations. 


\begin{tabular}{||r||r|r|r|r|r|r||}
\hline \multicolumn{7}{|c|}{ Table 6. Summary of Utterances* } \\
\hline $\begin{array}{c}\text { Conversation } \\
\text { number }\end{array}$ & Total & Tillie & Julie & Debi & Marie & Other \\
\hline 1 & 310 & 146 & 150 & N/A & N/A & 9 \\
\hline 2 & 236 & 90 & 99 & N/A & N/A & 47 \\
\hline 3 & 62 & 31 & 31 & N/A & N/A & N/A \\
\hline 4 & 121 & 60 & 61 & N/A & N/A & N/A \\
\hline 5 & 145 & 72 & N/A & 73 & N/A & N/A \\
\hline 6 & 120 & 60 & N/A & 60 & N/A & N/A \\
\hline 7 & 168 & 82 & N/A & N/A & 84 & 2 \\
\hline 8 & 106 & 52 & N/A & N/A & 54 & N/A \\
\hline
\end{tabular}

${ }^{*}(\mathrm{~N} / \mathrm{A}=$ not applicable. The person did not participate in the conversation)

Often, the turn taking that occurs between Tillie and her conversation partner reveals not only Tillie's basic sense of when it is her turn to speak, but also her ability to anticipate her partner's response. The result is a well paced series of exchanges with virtually no pause between utterances (see Appendix B for a discussion of transcription symbols).

Tillie: $\quad$....Have you seen Adele Syndelar?

Julie: $\quad$ Adele Syndelar? No, I haven't=

Tillie: $\quad=$ for ages, huh=

Julie: $\quad=$ not for ages, have you?

Tillie: $\quad$ Oh, I write to her every once in a while.

(Example 1, Conv. 1)

A second indicator of Tillie's ability to actively participate in the conversations is her ability to produce extended discourse. In six of the eight conversations, Tillie produces more words than her primary interlocutor. Many researchers have reported 
that people with Alzheimer's are verbose, stating that the high number of words they produce is a result of their tendency to circumlocute and unnecessarily repeat words and phrases. (Bayles and Kasniak, 1987; Sanderson, Obler and Albert, 1987; Smith Chenery and Murdoch, 1989). At first glance this appears to be true for Tillie as well. In the majority of conversations, Tillie produces more repeated phrases than her interlocutor.

\begin{tabular}{|r||r|r|r|r|r||}
\hline \multicolumn{6}{|c|}{ Table 7. Number of Repeated Utterances } \\
\hline \hline $\begin{array}{c}\text { Conversation } \\
\text { number }\end{array}$ & Total & \multicolumn{1}{|c|}{ Tillie } & \multicolumn{1}{c|}{ Julie } & \multicolumn{1}{c|}{ Debi } & Marie \\
\hline \hline 1 & 11 & 10 & 1 & N/A & N/A \\
\hline 2 & 4 & 3 & 1 & N/A & N/A \\
\hline 3 & 0 & & & & N/A \\
\hline 4 & 9 & 8 & 1 & N/A \\
\hline 5 & 6 & 5 & 1 & N/A & N/A \\
\hline 6 & 6 & 3 & N/A & 3 & N/A \\
\hline 7 & 6 & 5 & N/A & N/A & 1 \\
\hline 8 & 13 & 13 & N/A & N/A & 0 \\
\hline
\end{tabular}

However, most of her repetitions do not detract from the overall pace of the conversation ${ }^{1}$. In fact, these repetitions, while greater in number, are not unlike those produced by the healthy interlocutors (e.g. Julie: I studied I read I read my books).

Tillie: ...they came and I hurried and hurried and hurried and fixed a little (shrimp, unintelligible). (Example 2, Conv. 2)

Unlike Tillie's repetitions in the other conversations, most of those in conversation eight appear to be cases of perseveration. For example: "Well, you do. I don't know you're you're just just a dear girl looking." and "....she uh likes the one that ss he could takes two two ah two of (put/but) two of 'em...." 
Tillie: Well, I don't uh I don't want to get her scared or (anything like that).

(Example 3, Conv. 4)

A careful examination of the conversations suggests that while Tillie's speech is at times inefficient, perseveration is not the primary cause of Tillie's speaking more words than her interlocutor. Instead, Tillie's higher number of words reflects her role within the conversations. During most of the six social interactions, the primary interlocutors allow Tillie to establish the conversational frame. Therefore, Tillie carries the weight of the conversation, while the interlocutors respond and ask questions. For example, in Conversation Four, after the initial greeting exchange is completed, twenty four of Tillie's thirty-eight utterances center on her concern for her mother's illness.

Tillie: Uh huh. I'm (came) up with my mother in Ashland.

Julie: Are you. Do. You did?

Tillie: Uh huh.

Julie: How is she?

Tillie: Oh she's fine. She's not going to make it too much longer though. [Tillie's facial expression is sad]

Julie: She's not?

Tillie: No.

Julie: Is she not feeling well?

Tillie: Huh uh. She uh she used to talk and visit with other people Julie: Uh huh.

Tillie: for the (k) but now it's just oh she just gets so (f faint).

(Example 4)

The healthy interlocutor's contributions to this exchange are primarily questions and feedback that facilitate Tillie's discussion of her mother. In his research on care giver listening patterns, Bohling (1991) found that the responses of the listener had an effect on the Alzheimer's subject's level of participation in conversation. As was the case in Bohling's research, when Tillie's conversational partners accept and work within the 
topic frames she establishes, her level of participation increases and as a result, the quantity of words she uses also increases.

A third indicator of Tillie's active participation in the conversations is her role in nominating new topics and shifting current topics of conversations. In Conversation One, Tillie nominates an alternative to her interlocutor's topic nomination.

Julie: Let's have a seat.

John: Yeah. [Tillie, John and Julie sit]

Julie: Nice music.

Tillie: Do you like those cute little boys? [Tillie looks toward two men who are walking down the hall]

(Example 5)

Tillie shares equally in introducing new topics into the conversation. Table three outlines the number of topics nominated by each participant in the eight conversations. The high number of topic nominations in Conversation One reflect both the length of the conversation (seventeen minutes) and that fact that in several instances, two or three topics are nominated before one is finally accepted and developed. On the other hand, in Conversation Four fewer topics are nominated, but each topic is more fully developed. 


\begin{tabular}{||r||r|r|r|r|r|r||}
\hline \multicolumn{7}{|c|}{ Table 8. Summary of Topic Nominations } \\
\hline $\begin{array}{c}\text { Conversation } \\
\text { number }\end{array}$ & Total & \multicolumn{1}{|c|}{ Tillie } & \multicolumn{1}{c|}{ Julie } & Debi & Marie & Other \\
\hline 1 & 19 & 13 & 6 & N/A & N/A & 0 \\
\hline 2 & 13 & 4 & 6 & N/A & N/A & 3 \\
\hline 3 & 4 & 1 & 3 & N/A & N/A & N/A \\
\hline 4 & 4 & 3 & 1 & N/A & N/A & N/A \\
\hline 5 & 7 & 5 & N/A & 5 & N/A & N/A \\
\hline 6 & 7 & 4 & N/A & 3 & N/A & N/A \\
\hline 7 & 12 & 5 & N/A & N/A & 7 & N/A \\
\hline 8 & 8 & 6 & N/A & N/A & 2 & N/A \\
\hline
\end{tabular}

In several of the conversations, Tillie is aware of when the conversation is lagging and skillfully nominates a new topic, in order to stimulate it. For example, Tillie often nominates topics after a lengthy pause. In Conversation One, after a pause of eight seconds, Julie sighs loudly. Immediately after this sigh, Tillie nominates a new topic by asking her a question.

Tillie: but he isn't fast about doing things like that.

Julie: Mmhmm.

Tillie: You know it just.

[pause eight seconds, Julie sighs]

Tillie: What else is there new? How about [pause one second] Elmer?

(Example 6)

This ability to nominate topics at appropriate points in the conversation suggests that Tillie retains at least a partial awareness of the broader conversational context and the responsibility of each participant to engage their partner in the conversation. A second 
example of this awareness occurs when Tillie skillfully shifts the topic away from herself and onto her conversation partner. In this exchange, Julie has complimented Tillie several times about her hair.

Julie: Ah yes. It looks wonderful.

Tillie: I just got here. [Tillie pats her hair]

Julie: Did you get it done today?

Tillie: No, not just yet. Oh, I don't know.

Julie: You should look in the mirror, it looks wonderful.

Tillie: Well, I'm gonna look at yours. [Tillie pats Julie's hair]

Julie: Mine doesn't look very good. Mine's a mess.

(Example 7, Conv. 3)

Tillie's ability to take turns smoothly, to produce extended discourse on a subject, and to nominate and shift topics appropriately indicate that she can still actively participate in conversation. On the other hand, several aspects of her discourse reflect common deficits experienced by people with Alzheimer's.

An important finding of past Alzheimer's research has been that the discourse of people with Alzheimer's is either vague or uninformative. Their difficulty in producing appropriate words is a primary cause of their vague discourse. In addition, Ehernberger Hamilton (1994) writes that people with Alzheimer's cannot accurately assess how much background information a listener has. As a result, they often assume they are providing an adequate amount of information about a topic when in fact they are not. Tillie's language reflects these deficits in four respects.

First, she frequently uses pronouns without a clear referent. Sanderson, Obler and Albert's (1987) review of deficits in Alzheimer's language cites pronoun reference as one of the primary causes of unclear speech in Alzheimer's discourse. Table nine 
lists the number of pronouns Tillie produces with and without a clear referent. While she always produces more pronouns with reference than without, the number of pronouns without clear reference is high enough to cause problems in discourse coherence for her interlocutors. This is especially true for Conversation Eight in which 48 percent of Tillie's pronouns ( 21 of 45$)$ do not have a clear referent.

\begin{tabular}{||r||r|r|r|r|r|r|r|r||}
\hline \multicolumn{8}{|c|}{ Table 9. Summary of Pronoun Reference } \\
\hline \hline Pronoun Type & 1 & \multicolumn{1}{|c|}{2} & \multicolumn{1}{|c|}{3} & \multicolumn{1}{|c|}{4} & \multicolumn{1}{c|}{5} & \multicolumn{1}{c|}{6} & \multicolumn{1}{c|}{8} \\
\hline \hline With Referent & 45 & 18 & 5 & 37 & 18 & 14 & 12 & 24 \\
\hline $\begin{array}{c}\text { Without } \\
\text { Referent }\end{array}$ & 15 & 10 & 1 & 7 & 7 & 7 & 15 & 21 \\
\hline \hline Total & 60 & 28 & 6 & 44 & 25 & 21 & 28 & 45 \\
\hline
\end{tabular}

The majority of these instances are pronouns without antecedents, as in this example from Conversation One.

Tillie: Yeah [softly] It's comin up another one. [referring to a new day] Julie: Another one's comin'. What are you going to do?

Tillie: Teach. I don't know if they're going to teach with me or not. (Example 8)

In a few cases, Tillie appears to simply use the incorrect pronoun. In Conversation Six, when Tillie complains about her hair, she substitutes the pronoun your in place of $m y$.

Debi: You don't like your hair like this?

Tillie: Do you?

Debi: I like it, don't you?

Tillie: Well [pause two seconds]

Debi: Hmm?

Tillie: I don't think it looks nice on your face.

(Example 9)

A second deficit in Tillie's language is her use of empty or imprecise words. In 
example ten, Tillie's answer to a question is rendered meaningless by her use of pronouns without reference and the empty word thing.

Marie: Did you ever ride in a car like that? [Marie is pointing to a picture of a car in an old book]

Tillie: Well, (it depick) pick on the things that they want them to get, we get to 'em and.

(Example 10, Conv. 7)

Tillie often substitutes an empty word in place of an entire verb phrase. As with example 10, when this occurs in combination with other non-referenced words, the precise meaning of Tillie's utterance is lost.

Tillie: I don't know, I'd like to go. I haven't had a chance to do that, to do that go out. And uh (.) I do all this other stuff=

Julie: Mmhmm

Tillie: =but I'd like to go do it once in order to [pause one second] in [pause one second] then to me [pause one second] to [pause two seconds] daddy granddad he [Tillie begins to breathe heavily]

(Example 11, Conv. 1)

In addition to using empty words, Tillie uses semantically unrelated words and neologisms (created words). In some instances, Tillie's word choice may have a very distant relationship to the context of the utterance such as the possible relationship between "home" and "grass" in this exchange from Conversation Seven.

Marie: ....How are ya?

Tillie: Well, I'm home on this (ts ass) on the but I can't get on the grass right away.

Marie: You're home on the grass?

(Example 12)

In other instances, the word clearly has no semantic relation to the rest of the utterance. In example thirteen, John and Julie are discussing the nursing attendants who are standing around a cart, pouring juice and measuring medicine. 
Julie: It's a busy day today. Lots of action.

John: They're just passin' out medicine.

Julie: Uh huh. [pause two seconds] It's nice that they (unintelligible).

Tillie: The baking doing? Cooking? Is it the baby baking?

(Example 13)

Several utterances earlier, Tillie and Julie had talked about baking, therefore, Tillie's comments about baking in this exchange (The baking doing? Cooking?) may be connected to this previous discussion. However, Tillie's pairing of baby with baking seems to be an instance of producing a semantically unrelated word.

Ehernberger Hamilton (1994) writes that as her subject's language ability diminishes, the number of neologisms she produces increases. While Tillie does produce some neologisms (e.g. plient and chezuh), the number is still relatively small.

\begin{tabular}{|c||r|r|r|r|r|r|r|r||}
\hline \multicolumn{8}{|c|}{ Table 10. Number of Neologisms } \\
\hline \hline & 1 & 2 & 3 & 4 & 5 & 6 & 7 & \multicolumn{1}{c||}{8} \\
\hline Tillie & 10 & 2 & 0 & 8 & 2 & 0 & 12 & 8 \\
\hline
\end{tabular}

In some cases, the neologisms Tillie produces still manage to convey a meaning that is appropriate to the context of her utterance. These two examples from Conversation Five provide examples of this.

Tillie: Oh gosh. [spoken with upset intonation]

Debi: What's wrong?

Tillie: How come everything's so (swimbly) and everything. It makes me sick.

Tillie: See, I've got some t-t-twitch twincher here.

Debi: In your knee? 
Tillie: In my knees, every once in a while it goes off.

(Example 14)

When several of these language impairments surface in a single utterance or series of utterances, the conversation rather amazingly moves forward, but is highly incoherent. In the example below from Conversation Eight, Tillie uses pronouns without referents (he, she and it), empty words (those other ones, those little red ones) and neologisms (contrubary). She begins speaking after a short pause, but there is nothing in the preceding conversation that appears related to her utterances.

Tillie: Well, he $\mathrm{t}$ (.) she told me that soon as I (want) to, that she'd [Tillie clears her throat] the (students) and those other ones and those little red ones. That's all, it's all important. It's pul looks real good and I think that's right where I should (go).

Marie: It's all important. It looks very good and that's where you should go. Tillie: $\mathrm{Mmhmm}$ Mmhmm

Mmhmm.

Marie: Huh. That makes you happy?

Tillie: Hmmm?

Marie: That makes you happy?

Tillie: Well, (no), she's kind of a a stupid little girl. Real (con-contrub, contrubary)

(Example 15)

A final characteristic of Tillie's discourse is to discuss topics that are clear to the listener, but contextually impossible. These topics tend to be about people from Tillie's youth or recent social events. In example fifteen, Tillie mentions her-sister- in law, who has been dead for many years.

Tillie: What else do you know that's exciting? Have you seen Adele Syndelar?

Julie: Adele Syndelar? No, I haven't=

Tillie: =for ages, huh?=

Julie: =not for ages, have you?

Tillie: Oh, I write to her every once in a while. 
(Example 16)

Sperber and Wilson (1988) write that the primary responsibility for avoiding misunderstandings rests with the speaker. It is the speaker who must assess how much information the listener needs in order to understand the speaker's message. While not all of Tillie's language is as obscure as that which appears in example fifteen, clearly her ability to provide an appropriate amount of information is impaired. Therefore, the healthy interlocutors must choose either to accept a higher incidence of ambiguous or contextually impossible topics, or to expend a great deal of energy attempting to repair conversational confusion. Most often, the interlocutors attempt to accommodate Tillie's language by working within the framework she has established and thus manage to facilitate the overall conversation.

\section{FUNCTIONAL LANGUAGE}

\section{Conversational Maintenance}

One of the intriguing aspects of language produced by people with Alzheimer's is its combination of fluency with vague or implausible content. Some researchers have suggested that Alzheimer's language appears fluent because it is syntactically intact (Appell, Kertesz and Fisman, 1982). Others state that fluency is simply a result of verbosity caused by circumlocution and perseveration (Bayles and Kasniak, 1987). A third observation is that the language of people with Alzheimer's is fluent only when it involves conventionalized language such as greetings and accepting an apology (Fromm and Holland, 1989). While all these findings may accurately describe characteristics of 
Alzheimer's language, they do not capture that aspect of fluency that involves the ability to navigate one's way through a conversation. Nattinger and DeCarrico's (1992) category of conversational maintenance involves language that functions to operate the basic stages of an interaction; its opening, its forward progression and its closing. In other words, the primary scaffolding of a conversation. It is to these basic components of conversation that the discussion now turns.

Openings. Conversations are typically opened with a summons and a response to the summons. Past research on Alzheimer's language reports that this highly formulaic exchange remains intact until very late in the disease. It involves a sequence of lexical phrases that, as Crisp (1993) writes, can be performed "on automatic pilot" (p. 66). These phrases include the summons (e.g. "hey/hi/hello, (NAME)" or "how are you (doing)?"), and the response to summons ("hi/hello, (NAME)," "how are you," or "fine").

The opening exchange is successfully produced in each of the eight interactions in this study and generally follow a pattern similar to this example from Conversation Two. The lexical phrases that facilitate conversational functions are underlined when they occur in the exchanges throughout the remainder of the chapter.

Julie: Tillie?

Tillie: $\underline{\mathrm{Hi}}$.

Julie: Hello.

Tillie: How are you?

Julie: Good, how are you?

Tillie: Fine (unintelligible).

(Example 17)

This routine occurs at other points in the conversation as well. For instance, as 
with Ehernberger Hamilton's subject, Tillie uses this familiar routine as a means of socializing with people as they walk past. In addition, Debi (the caretaker) uses it not only as a greeting, but also at other points in the conversations to engage Tillie as she helps her prepare for bed.

Tillie: So I don't have it (unintelligible fit) like they do and I wish I could. I could (fix/fit) pretty part of this, it's be (one/nice) for that. [Tillie begins to hum to herself]

Debi: Tillie?

Tillie: What, honey?

Debi: How do you feel? How are you tonight?

Tillie: Just (.) Okay.

Debi: You're okay?

Tillie: Mmhmm.

Debi: Good. Good.

(Example 18)

The lexical phrases associated with this routine are central to its execution. In particular, the lexical phrase "How are you (time phrases)" enables Tillie to both initiate discourse and respond to openings initiated by other speakers.

Forward progression. Nominating and shifting topics is a second basic component of facilitating conversation. Nattinger and DeCarrico provide several examples of question frames that are used to nominate topics such as "What's X?" and "(by the way) do you know/remember X?" In this study, questions are the primary strategy used by Tillie and her interlocutors for nominating topics.

Tillie: Oh happy days are here again.

Julie: Oh are they?

Tillie: Mmhmm.

Julie: Singin a song.

Tillie: What did you do all day today?

Julie: I studied. I read I read my books. 
In the above example, Tillie uses the lexical phrases "What did you do (time/place)" to nominate a new topic into the conversation. Example nineteen also illustrates the point made in the previous section that Tillie retains an awareness of when the conversation is beginning to lag and a new topic is needed. In this exchange, the four utterances preceding Tillie's question are relatively empty and seem to function as little more than space fillers until a new topic is selected.

Of the seventy-four topics that are nominated, only eleven are not acknowledged by the listener. The responses of Tillie's interlocutors to newly nominated topics vary in the degree to which they are willing to pursue unclear or implausible topics. In some cases, an anomalous topic may continue for several utterances (example 20). In other cases, the interlocutor appears reluctant to positively respond to a new topic if it is anomalous (example 21), or unsure how to develop an unclear topic and as a result, the topic is dropped after only a few utterances.

Tillie: Yeah. [pause two seconds] Well, I like it here now and I like to be here because mother is doing better than I had.

Julie: Yeah.

Tillie: She's.

Julie: She's doing better than you had hoped?

Tillie: Well, they have one bed, that is two and she, no I think they put her in one $=$

Julie: Uh huh

Tillie: =because they didn't wanna=

Julie: =mess with two=

Tillie: =(have) two and I don't think it's good that way.

Julie: Oh really?

Tillie: If uh.

Julie: Hmmm.

Tillie: So I went down afterwards and talked to the doctor down there.

Julie: Mmhmm. 
Tillie: He said if I didn't think it was better, to (try) this other one.

Julie: Right, then they change.

Tillie: Oh yeah.

Julie: Yeah.

Tillie: He said, oh yeah, by all means Tillie, take her and put a nice (silk/self) uh (etching/edging) around, you know.

[This topic continues for seven more utterances]

(Example 20, Conv. 4)

Tillie: You didn't see anything of Erma or any of the girls?

Julie: Mmm. No, did you?

Tillie: Hmm.

Julie: Huh uh?

Tillie: $O$ h.

Julie: Did you?

Tillie: Huh uh.

Julie: Hmm.

Tillie: Well, huh [Tillie chuckles] that's the way it goes.

(Example 21, Conv. 2)

Tillie must also deal with newly nominated topics that are unclear. Similar to her interlocutors in such situations, Tillie responds by asking for clarification and attempting to carry on the conversation in spite of her confusion.

Julie: Mmhmm. [pause three seconds] Who made your nails orange?

Tillie: Huh?

Julie: Who made your fingernails orange?

Tillie: (My) orange?

Julie: Look at your fingernails, they're beautiful.

Tillie: Well, no I saw it.

Julie: Did you have them painted here?

Tillie: I saw it on a finger.

Julie: You saw these on someone's fingers?

Tillie: Uh huh.

Julie: And you said I want it also [Tillie laughs] and you went to the beauty parlor.

Tillie: Well, I don't know.

Julie: It just happened.

[The topic continues for eleven more utterances]

(Example 22, Conv. 1) 
There does not appear to be any pattern to which topics are accepted and developed more fully and which are either not acknowledged or not developed. What is striking is that such a large number of the utterances which function as topic nominations are acknowledged and responded to by each participant despite the confusing nature of their content.

A third important element of maintaining a conversation is clarifying misunderstandings. Clarifications include both those requested by the listener (example 23) and those offered by the speaker (example 24):

Marie: Well, my children are Aaron and Christy.

Tillie: Aaron and who?

Marie: Christy.

(Example 23, Conv. 7)

Tillie: Where did you go with it? Did you go away?

John: Hmm?

Tillie: Did you go away with it?

(Example 24, Conv. 2)

Several strategies for signaling confusion are used and recognized as requests for clarification, both by Tillie and her interlocutors. Rather than using lexical phrases such as "you mean X?", the interlocutors in this study most often requested clarification by repeating a portion of Tillie's utterance with question intonation.

Tillie: What else is new? How about [pause one second] Elmer?

Julie: How about Elmer?

Tillie: California. [Tillie chuckles]

Julie: Oh, Elmer in California?

Tillie: Mmhmm. I guess he's still around, huh?

(Example 25, Conv. 1)

Tillie also uses this strategy (see example 23) although less often. Her primary method 
for signaling confusion is the simple utterance "hmmm" or "huh" with question intonation. In the conversations between Tillie and Debi (Tillie's caretaker), the majority of clarification requests are both semantically and functionally sound. In these conversations, the topics center on highly familiar routines, such as dressing and washing, that are occurring in the immediate context.

Tillie: It looks a little bit too too sss (snaggy).

Debi: What is?

Tillie: My hair.

Debi: You don't like your hair like this?

Tillie: Do you?

(Example 26, Conv. 6)

Tillie: I did have my teeth just before I came here.

Debi: Hmmm?

Tillie: I have washed my teeth already.

(Example 27, Conv. 5)

In contrast, many of the topics in the other six conversations revolve around people and events not in the immediate environment.

Many of the clarification requests in conversations between Tillie and Julie or Marie proceed fairly smoothly, despite occurring within a larger series of utterances in which the topic is either implausible or not clearly stated. For example, in the exchange below, Tillie is describing a conversation she had "the other day" with some visitors in her home. The likelihood of Tillie's actually having carried on the conversation she is reporting is slim, yet as with the preceding examples, Julie's clarification request is successfully carried out.

Tillie: and then they wanted oh you got that at (sss sy) down at Syngroves or someplace.

Julie: Oh, uh huh, they wanted to know where you got it? 
Tillie: Yeah=

Julie: Uh huh.

Tillie: =and so I said well it's here (.) in this town.

(Example 26, Conv. 2)

Once again, it appears that the functional elements of the conversations continue to operate smoothly even though the content of the conversations is odd.

Closings. The final element of conversational maintenance is signaling the closing and final parting of the conversation. As with greetings, closings are highly formulaic routines and Tillie is able to use and respond to the associated language with ease. In example 29, Debi uses two lexical phrases to signal the closing of her conversation with Tillie, "good night" and "I'll see you (time phrase)." Tillie recognizes these signals and responds appropriately.

Debi: Okay Tillie. Good night. [pause one second] Good night.

Tillie: Good night.

Debi: I'll see you tomorrow.

Tillie: Okay.

Debi: Okay

Tillie: I love you.

Debi: I love you too.

Tillie: Tomorrow.

Debi: Okay.

Tillie: [begins to hum as Debi leaves]

(Example 29, Conv. 6)

In example 30, Julie does not use a specific lexical phrases to signal the conversation's close, but she does use a common closing strategy that involves describing activities she plans to do in the near future. Tillie also recognizes and responds to this indirect closing of the conversation.

Julie: I'm going to go do some other visiting and uh then I'm going to go home and study. 
Tillie: Well, bless you. You're a nice girl. I'm so glad I have you.

Julie: Well, I love you. [Julie stands up to kiss Tillie] I'm glad I have you Tillie.

Tillie: Okay.

Julie: Bye bye.

Tillie: [Tillie starts to sing] Happy days happy day ay ays.

Julie: Happy days [Tillie laughs] Bye bye

Tillie: Good bye.

(Example 30, Conv. 4)

Although the final closings in each of the conversations is initiated by the healthy interlocutors, closer inspection of the transcripts suggests that Tillie herself made several attempts to close conversations that were not followed up by her conversation partner. In the following example, Tillie uses a lexical phrase, "this has been $\mathrm{X}^{\prime \prime}$ to signal her desire to close the conversation.

Tillie: [coughs] Well, this has been a real nice thing to have happen to me. I was just anxious to see how you were $=$

Julie: Mmhmm.

Tillie: =and everything....

Forty three utterances later, after a six second pause, Tillie again attempts to close the conversation, this time using another lexical phrase "well, I was glad to X." The key to this lexical phrase as well the lexical phrase used in the preceding example is her use of past tense verb forms.

Tillie: Well, I was glad to do this, to be (.) for you to (.) come down here. (Example 31, Conv. 1)

Unfortunately, Tillie is equally unsuccessful in her second attempt and the conversation continues for an additional thirty utterances before the final closing is initiated by Julie. Not only does Tillie produce clearly formed lexical phrases to signal her desire to end the conversation, she also produces lexical phrases socially appropriate for a person 
hosting a visitor in her home who she wishes would leave. Had Tillie's interlocutor been more perceptive in recognizing Tillie's closing signals, she might have responded more appropriately and followed up Tillie's signal by ending the conversation.

Based on this analysis of the conversations, Tillie is able to both use and respond to functional language in a manner that allows her to share in the control of maintaining the conversation.

\section{Conversational Purpose}

Tillie's ability to recognize and manipulate language that functions to move the conversation forward appears to play a role in her overall fluency. Another aspect of fluency concerns not the flow of conversation, but the speaker's ability to use language to carry out particular communicative acts. For example, the speaker may wish to offer help or to assert an opinion regarding the current conversation topic. This section discusses how Tillie and her interlocutors use and respond to language that conveys specific communicative purposes within the conversations.

Ehernberger Hamilton (1994) remarks that part of what makes the Alzheimer's subject in her study enjoyable to talk with is that her ability to use language to express politeness remains intact until late in the disease.

Contributing to this overall ease in talk seems to be Elsie's use of positive politeness devices, such as compliments, expressions of appreciation to others, terms of endearment and light-hearted jokes.

(p. 150)

These language functions match several of those described within Nattinger and DeCarrico's (1992) category of conversational purpose. In the eight conversations in 
this study, Tillie remains able to express general politeness, to give and receive compliments and to express gratitude. Her ability to successfully carry out and respond to these language functions further suggests that she retains sensitivity to other participants in the conversation.

First, Tillie is able to express general politeness at appropriate times during the conversation. This includes verbally recognizing and praising the people around her. For example, while Debi is fixing Tillie's hair, Tillie encourages her with a lexical phrase that is commonly use to endorse a speaker's comment ("that's great/fine/just right"), but is instead endorsing Debi's action.

Debi: Do you like it with a little more lift?

Tillie: Uh huh.

Debi: It's kind of flat?

Tillie: Yeah.

Debi: Okay. [Debi continues to fluff Tillie's hair with a brush] Tillie: Well, that's that's (fine) just right.

(Example 32, Conv. 6)

Several seconds later, after Debi has finished brushing Tillie's hair, she asks Tillie how she likes it. Once again, Tillie utters a series of familiar phrases to politely express her opinion of Debi's hair styling efforts.

Debi: Do you like it? Do you like this one better?

Tillie: Well, Ilike that better do. It shows me better $=$

Debi: Yeah.

Tillie: = and it's different.

(Example 33)

Another example of Tillie's ability to express politeness occurs during the closing of Conversation Two when Julie remarks that she will visit Tillie again. Parting comments 
that refer to seeing one another again, such as Julie's I'll come back and see you again, are common. In this closing, Tillie politely responds to Julie's parting comment by inviting her to return "any time."

Julie: God bless you too. I'll come back and see you again. Tillie: Oh I want you to, any time.

Julie: I will. Bye bye.

(Example 34)

In addition to responding to her interlocutors with general politeness, Tillie also gives and receives compliments appropriately. Both Tillie and her interlocutors use the same lexical phrase frame for giving compliments: NP + BE/LOOK + ADJ. For example, after Marie and Tillie greet one another in Conversation Seven, Tillie compliments Marie (Gee, you look so nice). Tillie, upon receiving a compliment from Julie, skillfully responds with one of her own.

Julie: You look wonderful.

Tillie: Well, you do too.

Julie: Thank you.

(Example 35)

Julie's compliment conforms to the lexical phrase "you look + adjective." Tillie clearly recognizes the function of this lexical phrase and completes the routine with another common lexical phrases. Example 35 is part of a larger series of compliments discussed earlier in example seven in which Tillie, wishing to shift the focus of compliments away from herself, shifts the focus to Julie.

Julie: You should look in the mirror, it looks wonderful.

Tillie: Well, I'm gonna look at yours. [Tillie pats Julie's hair]

(Example 36)

Tillie's move to shift the compliment away from herself conforms to a more general 
convention of social interaction that one should not respond to a compliment by keeping the focus of conversation on oneself.

Tillie also uses lexical phrases successfully to express gratitude. The most common expression of gratitude is "thanks" which Tillie uses appropriately in Conversation Five after she has finished brushing her teeth.

Debi: Let me pour this out. Let's dry your hands. [Debi rubs Tillie hands with a towel]

Tillie: Thanks.

Debi: Your welcome.

Tillie: [Tillie chuckles] I love you.

Debi: I love you too, Tillie.

(Example 37)

Even in Conversation Three, in which Tillie is the most distracted at any time during the eight conversations, she manages to express her gratitude to Julie in the closing. She uses another lexical phrase to signal her gratitude: "thanks (very much/a lot) (for X)."

Julie: Bye bye.

Tillie: I love you.

Julie: I love you too.

Tillie: Thank you for being so nice.

Julie: Okay. Bye bye.

Tillie: Bye bye.

(Example 38)

These examples of general politeness, complimenting and expressing gratitude are evidence that Tillie is not only aware, but also able to appropriately manipulate language in order to fulfill one of the basic requirements of social interaction: expressing politeness to one's conversational partner.

A second component of social interaction involves signaling to the listener one's position relative to the content of the conversation. For example, the speaker can signal 
whether or not she agrees with an idea. She can also inform the listener if she does not know a piece of information or signal that she is uncertain about the content of an utterance. Informing the listener of one's position relative to the information in the conversation helps to establish boundaries of known and unknown information, which in turn helps guide the flow of information within the conversations.

As with functional language that is used to nominate and shift topics and to request clarification, this category of language illustrates that the function of an utterance can be successfully applied even though the information that forms the content of the conversation is contextually impossible or not clearly defined. Despite the implausible nature of many of the topics Tillie discusses, she continues to use lexical phrases both to define the boundaries of her knowledge and to signal the listener that certain utterances are opinions.

"I don't know" is one example of a phrase that falls into the functional category of defining one's knowledge boundaries. Tillie uses the phrase "I don't know" for two functions. First, she uses it to inform the listener that she does not have the information that has been requested of her by the speaker. In Conversation Seven, Marie asks Tillie for a piece of information about a person Tillie has been discussing. Tillie's response directly informs Marie that she does not have the requested information.

Marie: She has a lot of problems, does she?

Tillie: Well, I don't know, I don I couldn't get out of her [pause 2 seconds] this time yet.

(Example 39)

As is the case in example 39, many of the topics Tillie nominates and discusses 
are based on a reality or world that is not shared by her interlocutors. Ehernberger Hamilton (1994) describes such topics as fictitional. Nevertheless, Tillie's use of "I don't know" suggests that her "pool of knowledge," real or unreal, has limits. Another example of Tillie's sense of the boundaries of her knowledge occurs in Conversation One. Her response to the interlocutor's request for more information suggests that she expected the interlocutor to realize that she could not possibly have the requested information.

Tillie: She's he's gonna change something there for you. [spoken as a man walks past]

Julie: Ah, that's good. What's he gonna change?

Tillie: Idon't know it's him not me.

(Example 40)

A second function of "I don't know" in these conversations is to signal general uncertainty about an utterance. Far more instances of this function occur than instances in which Tillie directly states that she doesn't have the information. One example of the lexical phrase being used to express uncertainty occurs when Debi asks Tillie if she is ready for bed.

Debi: Do you want to lay down now?

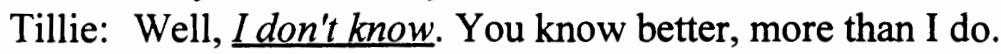

(Example 41, Conv. 6)

In some instances, Tillie seems to use "I don't know" as a way of signaling general confusion or uncertainty about how to respond to a previous utterance. In Conversation Seven, Marie is telling Tillie who her children are.

Marie: Well, my children are Aaron and Christy.

Tillie: Aaron and who?

Marie: Christy. 
Tillie: Well, Ldon't know. [spoken softly]

(Example 42)

A second set of lexical phrases that convey the speaker's attitude relative to the content of an utterance is "I think X" and "I don't think X." "I think X" is a lexical phrase that is used to signal that the utterance to follow is an opinion. In Conversation One, both Tillie and Julie use "I think" to convince a resident that a particular chair is comfortable enough for her to sit in.

Tillie: Is that good? [Tillie moves over on the sofa to make room for the resident]

Julie: I think there's room.

Tillie: I think this is comfortable.

Julie: I think it will be comfortable.

Tillie: Well, try it and see.

(Example 43)

All four participants use this phrase; however, Tillie produces it slightly more often that the three interlocutors. For example, in Conversation One, Tillie uses "I think" in five utterances, while Julie only produces it in three.

"I don't think X" combines an assertion with disagreement. This phrase which is only used by Tillie, occurs with the same frequency as "I think," and is Tillie's most common method of disagreeing. In Conversation Four, Tillie uses this phrase to express her disapproval of the way her mother's hospital room has been arranged.

Tillie: Well, they have her in one bed, that is two and she, no I think they put her in one $=$

Julie: Uh huh

Tillie: =because they didn't wanna=

Julie: =mess with two

Tillie: $=($ have) two, and $\underline{I d o n ' t ~ t h i n k}$ it's good that way.

(Example 44) 
In several utterances, Tillie sets up an assertion with either "I don't think" or "I think" yet at the point when the subject of the assertion would normally appear, Tillie's utterance becomes unintelligible or she simply leaves the phrase hanging. In Conversation Five, just as Tillie is about to explain why she feels confused (swimbly), her utterance becomes unintelligible.

Debi: What's wrong?

Tillie: How come everything's so (swimbly) and everything? It makes me sick.

Debi: What's wrong with you?

Tillie: Well, Liust think that I've been (unintelligible) (packing, wanted us to go camp, one of those people that) [spoken with downward intonation]

(Example 45)

In cases such as these, it appears that only the conversational scaffolding remains intact. Tillie is able to signal her opinion, or disagreement, but she has difficulty expressing the actual content. This lends further evidence to the broader finding that the functional framework of conversation remains intact despite the confused and unclear nature of many of the topics Tillie discusses.

A final area that is related to defining the boundaries of one's knowledge and controlling the flow of information concerns how the listener reacts when the conversational topic becomes unclear. Ripich and Terrell (1988) remark that a listener's judgment of discourse incoherence reflects the listener's level of tolerance for ambiguity. Past research has focused on the difficulty healthy listeners have in understanding vague or implausible discourse produced by Alzheimer's subjects. In this study, the interlocutors usually respond to unclear topics by requesting clarification, 
shifting the topic or simply "playing along" as though the topic were clearly understood. Throughout the eight conversations, Tillie also shows a limited tolerance for ambiguous topics, and uses several strategies to signal that she either doesn't understand the topic and/or wants to end it. Tillie uses some strategies that are similar to those of the healthy interlocutor such as requesting clarification and shifting the topic. In Conversation One, after a series of vague and somewhat purposeless utterances that were inspired by a comment Tillie made about an attendant that who had walked past, Tillie finally moves to shift the topic to something new.

Tillie: I might think if I took a second look then I'd. Might want to mock me.

Julie: Ah ha. Always have to be careful about that.

Tillie: I know it.

Julie: Never know what other people are going to say.

Tillie:

Well, I got you, that's what I'm loving at. Gosh, I was afraid sh they wouldn't see you for a long time, huh. (Example 46)

In other instances, Tillie is more direct in signaling that she does not understand or wants to end a particular topic. In Conversation Seven, Marie is asking Tillie about a picture of Tillie's church in her hometown. Although Tillie tries to signal her confusion by responding negatively to several of Marie's questions about the church, she finally resorts to expressing it more directly.

Marie: Is that your church?

Tillie: $H \mathrm{~mm}$ ?

Marie: Is that your Catholic church?

Tillie: $\mathrm{Hmm} \mathrm{mmm}$.

Marie: Right there $=$

Tillie: $\mathrm{Hmm} \mathrm{mmm}$

Marie: =in Hopewell?

Tillie: Idon't think. 
Marie: Nope it isn't.

Tillie: I can't [spoken softly]

Marie: Well, that little town had three Catholic churches.

Tillie: Idon't know what to think about that.

(Example 47)

The lexical phrases "I don't think" and "I don't know" occur in other exchanges in which

Tillie is signaling her negative relationship to the content of an utterance. In Example

47, Tillie appears to use the negative connotation of these lexical phrases as well as "I

can't" as signals to Marie that she either does not understand or does not which to

continue the topic.

Earlier in the conversation, when Marie first introduces the Hopewell book ${ }^{2}$,

Tillie uses a rather sophisticated technique to avoid discussing it by explaining that she is too busy, but would like to look at it later.

Marie: Here's a Hopewell book. Hopewell, South Dakota.

Tillie: Well, for goodness sakes.

Marie: How 'bout that?

Tillie: Well, that's interesting. Did that just come out?

Marie: No, it's about yesterday. [Marie turns the pages of the book]

Tillie: Well, I've gotta, may I take it home and look at it or=

Marie: Oh, that would be nice yeah.

Tillie: =and just look at it.

Marie: There's a lot of people in here from your home town (.) that you might recognize.

Tillie: Mmhmm.

Marie: I think you might recognize that person. [Marie points to a picture of Tillie's father.]

Tillie: Mmhmm. Yeah (now) I've got too many things to (do). I always have to get bogged down.

(Example 48)

Before the onset of Alzheimer's, Tillie used to enjoy talking about her hometown and looking at the pictures in this book. Perhaps this is why Marie makes several attempts to engage Tillie in conversation about it. 
Phrases such as "may I take it home and look at it" and "(now) I've got too many things to do" function to perform an indirect request to end the topic.

\section{Familiar Topics}

The final category of functional language that is analyzed in this study is familiar topics (referred to by Nattinger and DeCarrico (1994) as "necessary topics"). The category of familiar topics has a slightly different focus than the categories of conversational maintenance and conversational purpose. It includes language that is used to discuss topics that frequently arise during informal social interaction. These include discussions of likes and dislikes, the weather and shopping as well as other topics. Few lexical phrases appear in the conversations that correspond to the familiar topics outlined by Nattinger and DeCarrico (1992). The only phrases that occur consistently are those that function to state likes and dislikes (e.g. "I like X" and "I don't like X"). However, Nattinger and DeCarrico state that the list of topics they provide is not exhaustive, and a closer examination of the topics that are discussed reveals that Tillie uses a set of language to frame these topics much in the same way that lexical phrases mark the familiar topics outlined by Nattinger and DeCarrico.

Two topics that frequently appear in the eight conversations in this study are socializing and the preparation of food and doing housework. Ehernberger Hamilton (1994) notes that several segments of fluent language produced by the Alzheimer's subject in her study appear to be topically linked. Many of these chunks of fluent language relate to the subject's past professional life. Ehernberger Hamilton suggests 
that these chunks belong to a set of language sequences that have become conventionalized through years of discussing particular topics. In addition, she observes that they are often more fluent than the surrounding discourse.

Comments that center on socializing form some of the most fluent segments of language in Tillie's discourse. In addition to being a person who enjoyed socializing with others and entertaining guests, Tillie was also the wife of a small town doctor. This put her in a position of exchanging information with and about many people in the community. This example from Conversation Two illustrates the requests for information about people that Tillie often produces. The first utterance in this example is included to provide a contrast to the fluency of Tillie's request.

Tillie: Well, not only color, but it's (up there out the door) and [pause one second] we have $t$-to take care of ourselves about the water and all that right there.

Julie: Mmhmm.

Tillie: So

Julie: Yeah.

[Pause six seconds]

Tillie: You didn't see anything of Erma or any of the girls?

(Example 49, Conv. 2)

This stock request for information about "mutual acquaintances" is part of a larger repertoire of socializing language that includes comments about whether or not she has heard from people ("and so far I haven't heard from him"), corresponded with people ("Oh, I write to her every once in a while"), or visited people ("I just don't see any of them out here too much" ). Tillie's socializing language also includes comments regarding proper social behavior when talking about others.

Tillie: I shouldn't say anything, I do the (unintelligible, same thing). 
Tillie: Oh, she's got (big) things to cry about, I sh shouldn't have laughed like that.

(Example 50)

Another element of Tillie's socializing language is her recounting of conversations she has had with other people. These recountings are usually framed by what might be considered a lexical phrase: "(and/so) I/he/she told/said/asked X." Although the conversations Tillie discusses are fictitional, her manner and the way in which she frames these recountings are identical to the frequent stories I heard from Tillie before she had Alzheimer's disease.

Julie: Do you hear back from her?

Tillie: Yes, I told her about you and she said oh gee, that'd be fun to see 'em. (Example 51, Conv. 1)

Julie: Oh, uh huh, they wanted to know where you got it.

Tillie: Yeah.

Julie: Uh huh.

Tillie: And so I said well it's here (.) in this town.

(Example 52, Conv. 2)

Tillie: And so we I asked them why don't we just take those for show? So that's what he she did today.

(Example 53, Conv. 8)

A second set of fluent language that is associated with a familiar topic centers on preparing food and doing housework. As with Tillie's socializing language, these chunks are often mixed in with, yet more fluent than the surrounding discourse. In the example below, Tillie is explaining how she prepared a meal for guests.

Tillie: and it could be a kind of treat maybe

Julie: Mmhmm.

Tillie: 'cuz I'd done it before and it took (.) (put in) about two and a half (.) (ow ow hours) to do=

Julie: Mmhmm. 
Tillie: and so I was just breaded it and then this just (unintelligible) and then [Tillie chuckles] they came and I hurried and hurried and hurried and fixed a little (shrimp) (unintelligible).

(Example 54, Conv. 2)

Often, Tillie's references to cooking and housework convey either a lack of time (e.g. "I hurried and hurried and hurried....") or her effort to complete tasks.

Marie: I think you might recognize that person.

Tillie: Mmhmm. Yeah (now) I've got too many things to (do). I always have to get bogged down.

Marie: Did you ever ride in a car like that?

Tillie: Well, (it depick) pick on the things that they want them to get, we get to 'em and.

(Example 55, Conv. 7)

Tillie: Its I've got all my things done on (it) and I just like to get things done. Everything all gonna take home.

(Example 56, Conv. 5)

Tillie: Well, it's kind of nice to do that (.) and Johnny makes Johnny do that. I was getting it all ready and had things all out and I said well, I I'm ready now. I got my (hams) are ready and everything.

(Example 57, Conv. 8)

The specific topic of these utterances is not always clear, because they include pronouns without clear referents; however, the fluent segments within the utterance provide clues which enable the interlocutor to extend the discourse. Examples of how the interlocutors try to use these topical clues to facilitate the conversation occur below.

Tillie: I knew what she was going to have and that but just used it up anyway and I baked it.

Marie: Oh, you baked it?

Tillie: Mmhmm.

Marie: I bet it's pretty tasty. You're a good cook.

Tillie: Well=

Marie: Cooker.

Tillie: =I just kind of talk to myself, I wonder if I could give that little (he, hemah, hema) not hemah (.) oh henai [Tillie's voice becomes frustrated] 
oh what is that how is that (fray) oh I'm not going to do any talking.

(Example 58, Conv. 7)

Tillie: What else do you know that's exciting? Have you seen Adele Syndelar? Julie: Adele Syndelar? No, I haven't=

Tillie: $=$ for ages, huh $=$

Julie: =not for ages, have you?

Tillie: Oh, I write to her every once in a while.

Julie: Mmhmm. You write letters?

Tillie: I do drop something=

Julie: Uh huh.

Tillie: =just a note.

Julie: That's nice.

(Example 58, Conv. 1)

The analysis of familiar topics that appear in the conversations do not provide as much evidence of Tillie's ability to use lexical phrases as appeared in the analysis of conversational maintenance and conversational purpose. The only lexical phrases she used consistently throughout the eight conversations were those related to expressing likes and dislikes. On the other hand, there is some evidence that Tillie maintains language that relates to topics she frequently discussed during her lifetime. Her fluent use of this language can provide clues to help her interlocutors decipher the topic of her utterances.

\section{Conclusion}

This analysis of Tillie's participation in eight conversations has revealed the following about her ability to use functional language. First, Tillie is able to use and respond to language that functions to maintain the forward progression of conversation. This finding concurs with past research regarding the ability of people with Alzheimer's to participate in highly formulaic routines such as opening and closing conversations. 
In addition, this study found that Tillie is also able to nominate new topics at appropriate points in the conversation as well as using functional language to request and offer clarifications.

Second, Tillie is able to use and respond to language that functions to signal the speaker's communicative purpose of particular utterances. For this study, two types of conversational purpose functional language were examined. First, Tillie produced language that functioned to express general politeness and gratitude and to give and receive compliments. Second, she used functional language to signal her attitude relative to the informational content of utterances within the conversations. The analysis revealed that while the topics of conversations were not always clearly defined or plausible, Tillie still used functional language to signal the boundary between known and unknown information as well as signaling assertions and agreement or disagreement. Third, Tillie maintained several sets of fluent chunks of language that were topically linked. This language is related to experiences in her life that were consistently and frequently discussed. Two specific topics for which Tillie had a large repertoire of these language chunks are socializing and the preparation of food and crafts.

Finally, lexical phrases played an important role in facilitating Tillie's use of functional language. Within the category of conversational maintenance, they provided the framework for opening the conversations (e.g. "how are you"), as well as signaling their close (e.g. "(it's been) nice talking to you"), and final parting (e.g. "good bye"). In addition, lexical phrases were the dominant strategy used by the participants to signal 
the nomination of new topic (e.g."What's new with you").

Lexical phrases were also central in signaling the conversational purpose of utterances. All forms of politeness that were directly expressed were done so through the use of lexical phrases (e.g. "you look wonderful"). In addition, Tillie used lexical phrases to signal the boundaries of her knowledge and to express uncertainty ("I don't know X"). They were also used for expressing disagreement (e.g. "I don't think X"). Finally, Tillie used several sentence frames to discuss familiar topics. For example, she used ("I like X") when discussing likes, and when recounting conversations to her interlocutor, she often used the sentence frame "(and/so) I/he/she/ told/ said/asked X."

The summary of Tillie's basic language skills presented at the beginning of this chapter, suggest that she suffers many of the language deficits commonly experienced by people with Alzheimer's. The frequency and type of deficits that occurred in her utterances, as well as the length of time she has had the disease indicate that while she has not yet reached an advanced stage of Alzheimer's, she clearly has progressed beyond the early or mild stage. Despite her language deficits, Tillie is still able to use and respond successfully to functional language. As a result, she is able to actively take part in the conversations. 


\section{CHAPTER V}

\section{CONCLUSIONS}

In a survey conducted by Bayles and Tomoeda (1991), 71 percent of caregivers responded that the person with Alzheimer's for whom they cared was not able to sustain a conversation. Likewise, many researchers of Alzheimer's language have reported that people with Alzheimer's lack the skills necessary to successfully participate in conversations. In contrast, this case study has found that the Alzheimer's subject retains certain language skills that facilitate her ability to actively take part in conversation. These contrasting findings reflect, in part, differing approaches to understanding how people with Alzheimer's use language. The discussion of language within caretaker literature is largely anecdotal. Friends and relatives who have communicated for years with a person, may feel especially frustrated when they are no longer able to communicate in quite the same manner as before the onset of Alzheiemer's disease. This struggle to communicate might lead them to feel that the person with Alzheimer's has lost their ability to converse.

The discussion of language within Alzheimer's research has focused largely on documenting the degeneration of specific language skills. While this information has been useful for those concerned with diagnosing the disease, it has not provided useful 
information for those interested in communicating with people who have Alzheimer's disease. Sabat (1991) writes that in order to communicate successfully communicate with a person who has Alzheimer's disease, a healthy interlocutor must have a sound knowledge of the linguistic deficits commonly experienced by people with Alzhemier's in addition to a strong desire to understand what the person with Alzheimer's is trying to say. It could be argued that in addition to these, the healthy interlocutor must also have a sound knowledge of the linguistic skills that remain intact.

The approach of this study has been to examine systematically the natural conversations of a person with Alzheimer's in order to provide documented evidence of communication skills that remain in place. Nattinger and DeCarrico's concept of lexical phrases facilitated this research approach in several ways. First, it provided a theoretical framework for examining the form and function of conventionalized language, a frequently cited but little researched feature of Alzheimer's language. Second, Nattinger and DeCarrico's characterization of functional language as the primary means by which conversation is guided provided a theoretical explanation for the concept of conversational scaffolding, a idea posited in Chapter One as a potential contributor to fluency in people with Alzheimer's disease.

This analysis revealed that the subject has an intact knowledge of functional language skills which allowed her to successfully particpate in conversation despite serious language deficits. Specifically, this study found that:

1. The subject retained skills necessary to share control in opening and closing conversations as well as in nominating and shifting topics and requesting and 
offering clarification;

2. The subject was able to use functional language to signal utterances intended to convey general politeness, gratitude and compliments as well as to inform the interlocutor of her attitude toward the content of utterances;

3. The subject was able to use functional language to a lesser extent to mark specific topics of discussion; and

4. Lexical phrases played a central role in facilitating the subject's use of functional language.

\section{IMPLICATIONS}

\section{Implications for Lexical Phrases}

In their discussion of lexical phrases, Nattinger and DeCarrico (1992) suggest that people draw on prefabricated chunks of language to perform specific, conventionalized functions in discourse. The application of the lexical phrase framework to people with Alzheimer's disease in this study revealed a close theoretical correspondence between descriptions of the types of memory and language processing skills most likely to remain intact in Alzheimer's disease and the distinguishing characteristics of lexical phrases which had not been previously established.

For example, Alzheimer's researchers have found that information that is frequently used over a long period of time is more likely to be preserved in memory than recent information or information that is not often used. Lexical phrases, as salient 
pieces of information that are employed often over the course of one's life, form a subset of knowledge that matches this preservation requirement. In addition, Alzheimer's research has observed that language that is more easily produced is less likely to be affected by the disease. Nattinger and DeCarrico maintain that lexical phrases are accessed and applied as chunks of information and therefore place less demand on language processing systems than language that is generated word by word. These parallels make people with Alzheimer's a particularly appropriate group to examine.

Language generated during the conversations in this study provided support for lexical phrases. While the content of her discourse was often vague or implausible, Tillie produced and responded to many conventionalized chunks of language that served specific functions within the conversations. These strings of words corresponded closely both in form and function to various types of lexical phrases outlined by Nattinger and DeCarrico. While lexical phrases were not the only language that remained intact, the fact that in each instance of their use they were clearly formed and appropriately applied suggests that they do form a body of knowledge that has remained in place.

Implications for Communication and Alzheimer's Disease

Analysis of Tillie's participation within open-ended conversations revealed not only that she was able to navigate her way through the conversations via functional language, but that she was able to appropriately use this functional language during exchanges in which the informational content of her utterances was unclear or 
implausible. Based on these findings, it appears that within conversation, the use of functional language occurs separately from the application of informational content and also remains intact longer. In this study, the separation of function from content was especially clear in instances of topic nomination, requests for clarification, signals of known and unknown information, assertions of opinions and the recounting of conversations.

The analysis also demonstrated that Tillie's ability to share control of conversations was not always recognized by those conversing with her. Several researchers of Alzheimer's interaction (Bohling, 1991; Ramanathan-Abbot, 1994) point out that negative assumptions about the ability of people with Alzheimer's to communicate can unintentionally alter the healthy interlocutor's communication behavior toward the person with Alzheimer's in a self-fulfilling manner. In Conversation One of this study, Tillie twice attempted to close the conversation using clear and appropriate signals (see page 93). These signals were not acknowledged by the interlocutor and Tillie was left no choice but to continue the conversation for an additional 83 utterances until the interlocutor decided to end the conversation. Incidents such as this suggest an underlying assumption of the healthy interlocutor that because the Alzheimer's subject is not always correctly oriented in time and place, he or she is not capable of sharing in control of the conversation.

This evidence suggests that interlocutors need to avoid assuming that because the content of conversation is vague or implausible, the person with Alzheimer's is incapable of participating in conversation. For example, throughout the eight 
conversations, Tillie used questions to nominate new topics which at times were implausible. When the interlocutors recognized these questions as Tillie's effort to maintain conversation and attempted to work within her informational context regardless of its plausibility, the conversations progressed and Tillie was able to be an active participant. On the other hand, when the interlocutors focused only on the implausibility of the content of Tillie's questions without recognizing their broader functional role within the conversation, the interaction became less active and Tillie's participation was reduced. By learning to recognize and respond to functional language, healthy interlocutors can positively facilitate the person with Alzheimer's participation within conversation.

The use of functional language plays a subtle, yet important role in establishing a framework within which speakers conduct conversation. Tillie's ability to appropriately employ functional language allowed her to take part in forming this conversational framework. In addition, her ability to use and respond to functional language within conversation suggests that she maintains an awareness of the social nature of interaction and the interplay that occurs between the participants. Ehernberger Hamilton (1994) remarks that her subject's ability to use conventionalized language enabled her to interact with others and maintain her position as a social being. By focusing on the ability of people with Alzheimer's to transmit information efficiently, many researchers have overlooked the social function of interaction.

Halliday (1977) states that adults often focus on the referential function of language while neglecting the importance of other functions of interaction. For 
example, "small talk" is often dismissed as inconsequential because its primary function is to maintain or establish social relationships rather than imparting new information. Moreover, while a great deal of daily conversation may appear, superficially to be referential, in fact it is actually being used to indicate social solidarity. Participants may obtain new information; however, the primary satisfaction comes from having made some kind of social connection with the other participant (Wardhaugh, 1985). While the information people with Alzheimer's transmit while conversing may at times be unclear or implausible, it does not diminish their need to have and maintain social relationships with others through conversation. Interlocutors who recognize and use functional language while interacting with people who have Alzheimer's can facilitate their successful particpation in conversations and thus enable them to maintain social bonds.

\section{LIMITATIONS}

The methodology selected for this research project imposes several limits. First, the use of a single case study limits the extent to which the findings on the use of functional language can be applied to other people who have Alzheimer's disease. The intent of this research project is not to make a general statement about the ability of all people with Alzheimer's disease to use functional language in conversation, rather it has been to explore and describe an aspect of language use that has not been fully examined in the Alzheimer's language research in an effort to add another dimension to the 
growing information on language use in the natural conversations of people with Alzheimer's disease.

The second limitation concerns issues of reliability. First, the transcripts which formed the foundation of this interaction analysis include only 96 minutes of conversation. While clear patterns of communication did emerge from this set of data, a greater total length of conversations might have yielded more reliable results. Second, the personal relationship of the researcher to the subject might have favorably biased the researcher's perception of the subject's ability to communicate successfully. In his discussion concerning subjectivity in case study research, Nunan (1992) suggests that the researcher follow a clear and detailed framework for analyzing the data. This study followed the framework of functional language described by Nattinger and DeCarrico (1992) in Lexical Phrases and Language Teaching. In addition, examples from the transcripts are included to support each point that is made in the discussion of research findings.

\section{SUGGESTIONS FOR FURTHER RESEARCH}

Based on the positive results of this study, more research is needed at the interaction level. Additional case studies of natural interaction may uncover other communicative skills that remain intact in people with Alzheimer's or lend further support to the intact knowledge of functional language skills. The findings reported in this study only begin to tap the many dimensions of functional language used by people 
with Alzheimer's. Three specific suggestions for futher research are given below. 1. Although there were three different interlocutors involved in this study, there was not time or space to fully explore the differences in the interactions between the subject and the three interlocutors. The only documented difference found in this study involved the use of clarification requests. In the conversations involving Tillie and her caretaker, the requestions for clarification were both functionally and contextually sound. In contrast, in the conversations between Tillie and Marie or Julie, the requests were functionally sound, but tended involve unclear or implausible content. Further research on differences in the use of functional language among several interlocutors could be useful as well as interesting.

2. Several types of lexical phrases were not included in this study due to lack of time and space, yet casual observation of them within the transcripts suggests their analysis might prove interesting. In particular, an examination of questions and responses from the functional perspective of lexical phrases would provide a useful supplement to Ehernberger Hamilton's (1994) extensive work on question and response sequences. In addition, "requesting," "offering," "complying," and "refusing" were also neglected in this study. Insight into how these functions are used and responded to by people with Alzheimer's could be especially useful for caregivers.

3. In this study, breakdowns of the subject's utterances appeared to be of two types. First, many of the utterances began intelligibly, but ended either with an unintelligible sequence or an empty word (e.g. "I was just saying that you oughta (unintelligible)). Second, the subject began utterances but simply left them hanging (e.g. "well, it gives 
him a chance to...") In some cases this pattern included a lexical phrases that was well formed followed by an unintelligible sequence or empty word. This pattern also appeared in the discourse of other residents whose comments were recorded while they were standing near the tape recorder. A more systematic study of the relationship between lexical phrases and breakdowns in intelligiblity is another potential area of research. 


\section{BIBLIOGRAPHY}

Appell, J., Kertesz, A. and M. Fisman. 1982. A study of language functioning in Alzheimer patients. Brain and Language, 17, 73-91.

Bayles, K. 1985. Communication in Dementia. In H. Ulatowska (ed.) The Aging Brain: Communication in the Elderly. San Diego: College-Hill Press.

Bayles, K., and A. Kaszniak. 1987. Communication and Cognition in Normal Aging and Dementia. Boston: Little, Brown and Company.

Bayles, K. and C. Tomoeda. 1991. Caregiver report of prevalence and appearance order of linguistic symptoms in Alzheimer's patients. The Gerontologist Society of America, 31(2), 210-215.

Beck, J. (ed.) 1991. Geriatrics Review Syllabus: A core curriculum in geriatric medicine. New York: American Geriatrics Society.

Becker, R. and E. Giacobini (eds.) 1990. Alzheimer's Disease: Current Research in Early Diagnosis. New York: Taylor and Francis.

Blanken, G., Dittmann, J., Hass, J. and C. Wallesch. 1987. Spontaneous speech in senile dementia and aphasia: Implications for a neurolinguistic model of language production. Cognition, 27, 247-274.

Bohling, H. 1991. Communication with Alzheimer's patients: an analysis of caregiver listening patterns. International Journal of Aging and Human Development, 33(4), 249-267.

Capella, J. 1985. The management of meaning. In M. Knapp and G. Miller (eds) Handbook of Interpersonal Communication. Beverly Hills: Sage Publications.

Clem, R. 1991. Speech and hearing deficits in Alzheimer's disease. In R. Dippel and T. Hutton (eds) Caring for the Alzheimer's Patient. Buffalo: Prometheus Books.

Cohen, G. 1988. The Brain in Human Aging. New York: Springer Publishing 
Company.

Craig, R. and K. Tracy. 1983. Conversational Coherence: Form, Structure and Strategy. Beverly Hills: Sage Publications.

Crisp, J. 1993. Enhancing communication with people with Alzheimer's. Australian Journal of Communication, 20(1), 63-70.

Cronen, V., Pearce, B. and L. Harris. 1982. The coordinated management of meaning: a theory of communication. In F. Dance (ed.) Human Communication Theory: Comparative Essays. New York: Harper and Row.

Dippel, R. and T. Hutton (eds). 1991. Caring for the Alzheimer Patient. Buffalo: Prometheus Books.

Dorval, B. (ed). 1990 Conversational Organization and Its Development. Vol. XXXVIII, Norwood, New Jersey: Ablex Publishing Company.

Edmondson, W. 1981. Spoken Discourse: A model for analysis. London: Longman Group Ltd.

Edwards, A. 1993. Dementia. New York: Plenum Press.

Ehernberger Hamilton, H. 1994. Conversations with an Alzheimer's patient: An interactional sociolinguistic study. Cambridge: Cambridge University Press.

Evans, D. et al. 1990. Estimated prevalence of Alzheimer's disease in the United States. The Milbank Quarterly, 68 (2), 267-289.

Fromm, D. and Holland. 1989. Functional communication in Alzheimer's disease. Journal of Speech and Hearing Disorders, 54, 535-540.

Glickstein, J. 1988. Therapeutic Intervention in Alzheimer's Disease: A program of functional communication skills for activities of daily living. Rockville, MD: Aspen Publishers.

Green, G. 1989. Pragmatics and Natural Language Understanding. Hillsdale, New Jersey: Lawrence Erlbaum Associates.

Goffman, E. 1981. Forms of Talk. Philadelphia: University of Pennsylvania Press. 
Goodwin, C. 1981. Conversational Organization: Interactions between speakers and hearers. New York: Aldine De Gruyter.

Goodglass, H. and E. Kaplan. 1972. Assessment of Aphasia and Related Disorders. Philadelphia: Lea and Febiger.

Goodwin, C. 1986. Audience diversity, participation and interpretation. Text, 6(3), 283-316.

Grice, H.P. 1975. Logic and conversation. In P. Cole and J.L. Morgan, Syntax and Semantics, vol. III, 41-58.

Grosse, D., Gilley, D. and R. Wilson. 1991. Episodic and semantic memory in early verses late onset Alzheimer's disease. Brain and Language, 41, 531-537.

Grove, T. 1991. Dyadic Interaction: Choices and Change in Conversations and Relationships: W.M.C. Brown Publishers.

Halliday, M. and R. Hasan. 1976. Cohesion in English. Hong Kong: Longman Group LTD.

Halliday, M. 1977. Explorations in the Functions of Language. New York: Elsevier North Holland.

Hart, S. and J. Semple. 1990. Neuropsychology and the Dementias. London:Taylor and Francis.

Hatch, E. 1992. Discourse and Language Education. Cambridge: Cambridge University Press.

Heller, R., Dobbs, A. and G. Rule. 1992. Communicative function in patients with questionable Alzheimer's disease. Psychology of Aging, 7(3), 395-400.

Henig, R. 1981. The Myth of Senility. Garden City: Anchor Press/Doubleday.

Heston, L., and J. White. 1991. The Vanishing Mind: A Practical Guide to Alzheimer's Disease and Other Dementias. New York: W.H. Freeman and Company.

Hier, D., Hagenlocker, K. and A. Shindler. 1985. Language disintegration in dementia: effects of etiology and severity. Brain and Language, 25, 117 133.

Jackson, J., Katzman, R. and P. Lessin. 1991. Alzheimer's Disease: Long Term Care. 
San Diego: San Diego State University Press.

Jackson, S., Jacobs, S. and A. Rossi. 1987. Conversational relevance: three experiments on pragmatic connectedness in conversation, Communication Yearbook, 10,

Jarvik, L. 1987. How do we recognize this enemy? In Kalicki, A. (ed.) Confronting Alzheimer's Disease. Washington D.C.: National Health Publishing Company.

Jorm, A. 1987. A Guide to the Understanding of Alzheimer's Disease and Related Disorders. Washington Square: New York University Press.

Kawas, C. 1990. Early clinical diagnosis: status of NINCDS-ARDA criteria. In Becker, R. and E. Giacobini (eds) Alzheimer's disease: Current Research in Early Diagnosis. New York: Taylor and Francis.

Kempler, D., Curtiss, S. and C. Jackson. 1987. Syntactic preservation in Alzheimer's disease. Journal of Speech and Hearing Research, 30, 343-350.

Langer, E. 1978. Rethinking the role of thought in social interaction. In Harvey, J., Ickes, W. and R. Kidd (eds) New Directions in Attribution Research, 2, 35-37.

Larsen-Freeman, D. and M. Long. 1991. An Introduction to Second Language Acquisition Research. London: Longman Press

Mace, N. and P. Rabins. 1991. The 36 Hour Day. Baltimore: The Johns Hopkins University Press.

McLaughlin, M. 1984. Conversation: How Talk is Organized. Beverly Hills: Sage Publications.

Mitchell, D. 1991. Memory and language deficits in Alzheimer's disease. In R. Dippel and T. Hutton (eds) Caring for the Alzheimer's Patient. Buffalo: Prometheus Books.

Morris, R. and M. Kopelman. 1986. The memory deficits in Alzhiemer's-type dementia: a review. The Quarterly Journal of Experimental Psychology, 35A, 575-602.

Murdoch, B., Chenery, H., Wilks, V. and R. Boyle. 1987. Language disorders in dementia of the Alzheimer type. Brain and Language, 31, 122-137. 
Nattinger, J. and J. DeCarrico. 1992. Lexical Phrases and Language Teaching. Oxford: Oxford University Press.

Nebes, R., Martin, D. and L. Horn. 1984. Sparing of semantic memory in Alzheimer's disease. Journal of Abnormal Psychology, 93 (3), 321-330.

Nicholas, M., Obler, L., Albert, M. and N. Helm-Estabrooks. 1985. Empty speech in Alzheimer's disease and fluent aphasia. Journal of Speech and Hearing, 28, 405-410.

Nunan, D. 1992. Research Methods in Language Learning. Cambridge: Cambridge University Press.

Office of Technology Assessment. 1987. Losing a Million Minds: Confronting the tragedy of Alzheimer's disease and other dementias. Washington, DC: United States Government Printing Office.

Planalp, S., Graham, M. and L. Paulson. 1987. Cohesive devices in conversations. Communication Monographs, 54(4), 325-343.

Plum, F. (ed.) 1988. Language, Communication and the Brain. New York: Raven Press.

Powell, L. 1993. Alzheimer's Disease:A Guide for Families. New York:AddisonWesley Publishing Company.

Psathas, G. (ed.) 1990. Studies in Ethnomethodology and Conversational Analysis: Interaction Competence. Lanham: The International Institute for Ethnomethodology and Conversational Analysis and University Press of American Inc.

Ramanthan-Abbot, V. 1994. Interactional differences in alzheimer's discourse: an examination of AD speech across two audiences. Language in Society, 23 (1), 31-58.

Ripich D. and B. Terrel. 1988. Patterns of discourse cohesion and coherence in Alzheimer's disease. Journal of Speech and Hearing Disorders, 53, 8-15.

Ripich, D., Vertes, D., Whitehouse, P., Fulton, S. and B. Ekelman. 1991. Turntaking and speech act patterns in the discourse of senile dementia of the Alzheimer's type patients. Brain and Language, 40, 330-343.

Roberts, J. 1991. Taking Care of Caregivers. Palo Alto: Bull Publishing Company. 
Sabat, S.R. 1991. Facilitating conversation via indirect repair. The Georgetown Journal of Language and Linguistics, 2(3-4), 284-296.

Sabat, S.R. 1991. Turn-taking, turn-giving and Alzheimer's disease. The Georgetown Journal of Language and Linguistics, 2, 161-175.

Sandson, J., Obler, L. and M. Albert. 1987. Language changes in healthy aging and dementia. In Rosenberg, S. (ed.) Advances in Applied Psycholinguistics, Vol. I. Cambridge: Cambridge University Press.

Schegloff, E. 1968. Sequencing in conversation openings. American Anthropologist, 70, 1075-1093.

Schegloff, E. and H. Sacks. 1973. Opening up closings. Semiotica.

Schiffrin, D. 1987. Discourse Markers. Cambridge: Cambridge University Press.

Schiffrin, D. 1991. Conversational analysis. Annual Review of Applied Linguistics, 11, 3-16.

Schneider, W. and D. Schiffrin. 1977. Controlled and automatic human information processing: detection, search and attention. Psychological Review, 84, 1-66.

Searle, J. 1975. Indirect speech acts. In P. Cole and J. Morgan (eds) Syntax and Semantics, vol. III, 59-82.

Sloan, P. 1990. The normal brain: an overview. In R. Hamdy, J. Turnbull, L. Norman, and M. Lancaster (eds), Alzheimer's Disease: A Handbook for Caregivers. St. Louis: The C.V. Mosby Company.

Smith, S., Chenery, H. and B. Murdoch. 1989. Semantic abilities in dementia of the Alzheimer type. Brain and Language, 36, 533-542.

Sperber, D. and D. Wilson. 1986. Revelance: Communication and Cognition. Cambridge, Mass.: Harvard University Press.

Stillings, N., Feinstein, M., Garfield, J., Rissland, E., Rosenbaum, D., Weisler, S. and L. Baker-Ward. 1989. Cognitive Science: An introduction. Cambridge, Mass.: The MIT Press.

Tannen, D. 1989. Talking Voices: Repetition, Dialogue, and Imagery in Conversational Discourse. Cambridge: Cambridge University Press. 
Taylor, T. and D. Cameron. 1987. Analyzing Conversation: Rules and Units in the Structure of Talk. Oxford: Pergamon Press.

Ulatowska, H. (ed.) 1985. The Aging Brain: Communication in the Elderly. San Diego: College-Hill Press.

Ulatowska, H., Allard, L., Reyes, B., Ford, J. and S. Chapman. 1992. Conversational discourse in aphasia. Aphasiology, 6(3), 325-331.

Wardhaugh, R. 1985. How Conversation Works. Oxford: B. Blackwell.

Werth, P. (ed.) 1981. Conversation and Discourse: Structure and Interpretation. New York: St. Martin's Press.

Whitaker, H. 1976. Studies in Neurolinguistics, 2, 1-58. 
APPENDIX A

COOKIE THEFT PICTURE 
APPENDIX A

COOKIE THEFT PICTURE

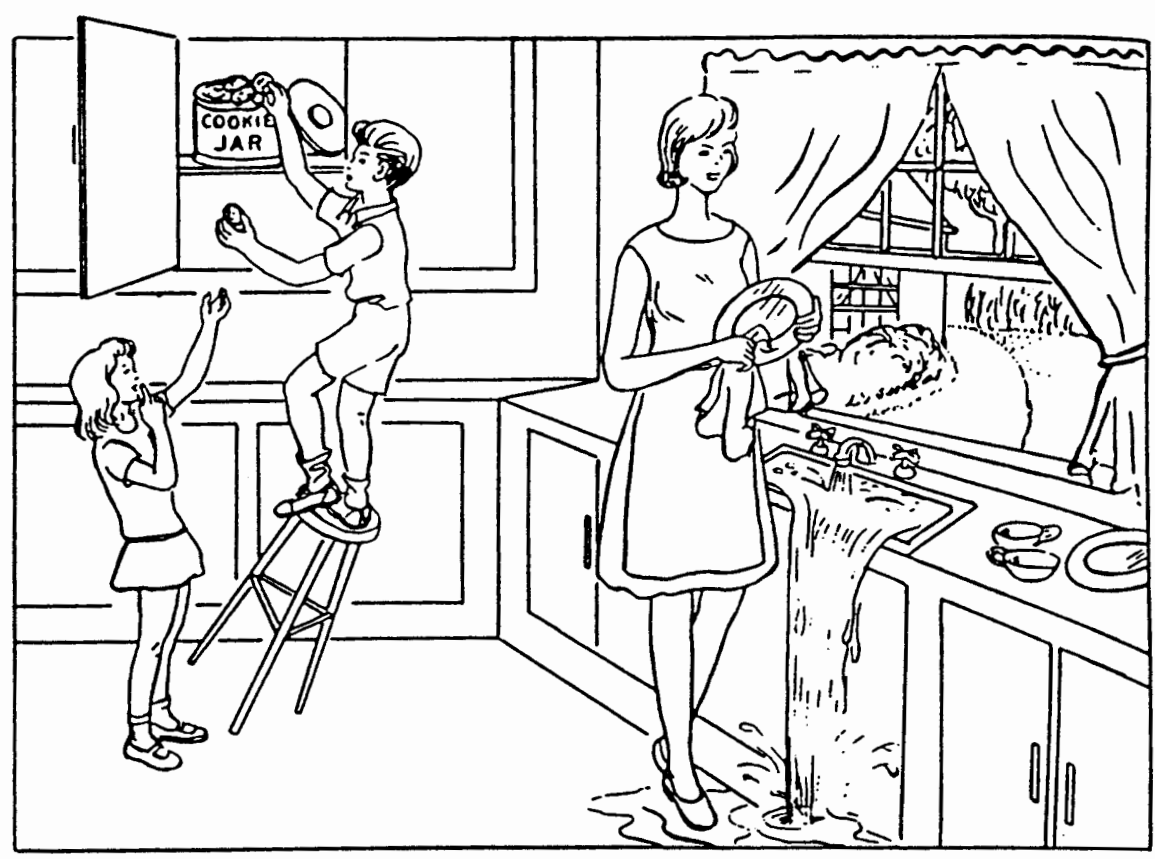

(Sanderson, Obler and Albert, 1987) 


\section{APPENDIX B \\ TRANSCRIPTION SYMBOLS}

The transcription symbols used in this thesis are based on the system developed by Jefferson (see Atkinson and Heritage, 1984) and reccommended by Evelyn Hatch (1992) in Discourse and Language Teaching. This system was chosen because the symbols are efficient and do not interfere with reading the content of the text. Some of the symbols have been modified to make them more relevent to this transcription task.

1. Large bracket indicates two people speaking simultaneously.

Example:

Julie: Mmhmm. I've been up talking

Tillie: $\quad$ got a chance to run the. .

2. An equal sign indicates that there is no gap between utterances.

Example:

Julie: Thank you=

Tillie: =I was just saying you oughta...

3. Single parentheses are used when the transcriber is unsure of accuracy.

Example:

Tillie: He likes to do those things.

Debi: Who?

Tillie: (Him).

Because Tillie uses many neologisms (created words), many of the "words" within parenthesis are informal phonetic approximations of what Tillie said. While it is not within the scope of this thesis, it is interesting to note that some of these neologisms seem to have a phonetic connection to the surrounding conversation. 
4. Single parentheses are also used when the word or words can not be understood.

This occurs for several reasons such as when the speaker mumbles, or there is too much background noise, or the tape recorder malfunctions. In these cases

"unintelligible" appears between the parentheses.

Example:

Julie: Good, how are you?

Tillie: Fine (unintelligible)

5. A slash mark between two words indicates that either one or the other of the words could have been spoken.

Example:

Tillie: Well, I don't know (need/leave) it right there.

6. Brackets indicate nonverbal sounds or particular intonation patterns.

Example:

Tillie: [softly] I don't like it like that.

7. Brackets also indicate gestures and environmental factors relevant to the conversation.

Example:

Julie: Tillie? [Julie touches Tillie on the shoulder]

8. Uppercase type is used for stress (pitch and volume)

Example:

Julie: Those ARE cute little boys.

9. (.) indicates a pause which is under one second.

Example:

Tillie: 'cuz I'd done it before and it took (.) (put in) about two and a half seconds. 